\title{
THE
}

2014

\section{Three-Dimensional Double-Ridge Internal Tide Resonance in Luzon Strait}

Maarten C. Buijsman

Jody M. Klymak

Sonya Legg

Matthew H. Alford

David Farmer

University of Rhode Island, farmerd@uri.edu

See next page for additional authors

Follow this and additional works at: https://digitalcommons.uri.edu/gsofacpubs

\section{Citation/Publisher Attribution}

Buijsman, M. C., Klymak, J. M., Legg, S., Alford, M. H., Farmer, D., MacKinnon, J. A., Nash, J. D.,...Simmons, H. (2014). Three-Dimensional Double-Ridge Internal Tide Resonance in Luzon Strait. J. Phys. Oceanogr., 44, 850-869. doi: 10.1175/JPO-D-13-024.1

Available at: https://doi.org/10.1175/JPO-D-13-024.1

This Article is brought to you for free and open access by the Graduate School of Oceanography at DigitalCommons@URI. It has been accepted for inclusion in Graduate School of Oceanography Faculty Publications by an authorized administrator of DigitalCommons@URI. For more information, please contact digitalcommons-group@uri.edu. 


\section{Authors}

Maarten C. Buijsman, Jody M. Klymak, Sonya Legg, Matthew H. Alford, David Farmer, Jennifer A.

MacKinnon, Jonathan D. Nash, Jae-Hun Park, Andy Pickering, and Harper Simmons 


\title{
Three-Dimensional Double-Ridge Internal Tide Resonance in Luzon Strait
}

\author{
MaArten C. Buijsman, ${ }^{*}$ Jody M. KlymaK, ${ }^{+}$Sonya LegG, ${ }^{*}$ Matthew H. Alford, ${ }^{@}$ \\ DAVID FARMER, ${ }^{\&}$ JENNIFER A. MACKINNON, ${ }^{* *}$ JONATHAN D. NASH, ${ }^{++}$JAE-Hun PARK, \\ ANDY PICKERING, ${ }^{@ @}$ AND HARPER SIMMONS ${ }^{\& \&}$ \\ * University of New Orleans, New Orleans, Louisiana \\ ${ }^{+}$University of Victoria, Victoria, British Columbia, Canada \\ "Princeton University, Princeton, New Jersey \\ ${ }^{\circledR}$ Applied Physics Laboratory, and School of Oceanography, University of Washington, Seattle, Washington \\ ${ }^{\&}$ University of Rhode Island, Kingston, Rhode Island \\ ** Scripps Institution of Oceanography, University of California, San Diego, La Jolla, California \\ ${ }^{++}$College of Ocean and Atmospheric Science, Oregon State University, Corvallis, Oregon \\ \#\# Korea Institute of Ocean Science and Technology, Ansan, Gyeonggi-do, South Korea \\ ${ }^{@ @ S c h o o l ~ o f ~ O c e a n o g r a p h y, ~ U n i v e r s i t y ~ o f ~ W a s h i n g t o n, ~ S e a t t l e, ~ W a s h i n g t o n ~}$ \\ \&\& University of Alaska Fairbanks, Fairbanks, Alaska
}

(Manuscript received 20 January 2013, in final form 8 November 2013)

\begin{abstract}
The three-dimensional (3D) double-ridge internal tide interference in the Luzon Strait in the South China Sea is examined by comparing 3D and two-dimensional (2D) realistic simulations. Both the 3D simulations and observations indicate the presence of 3D first-mode (semi)diurnal standing waves in the 3.6-km-deep trench in the strait. As in an earlier 2D study, barotropic-to-baroclinic energy conversion, flux divergence, and dissipation are greatly enhanced when semidiurnal tides dominate relative to periods dominated by diurnal tides. The resonance in the $3 \mathrm{D}$ simulation is several times stronger than in the $2 \mathrm{D}$ simulations for the central strait. Idealized experiments indicate that, in addition to ridge height, the resonance is only a function of separation distance and not of the along-ridge length; that is, the enhanced resonance in $3 \mathrm{D}$ is not caused by 3D standing waves or basin modes. Instead, the difference in resonance between the 2D and 3D simulations is attributed to the topographic blocking of the barotropic flow by the 3D ridges, affecting wave generation, and a more constructive phasing between the remotely generated internal waves, arriving under oblique angles, and the barotropic tide. Most of the resonance occurs for the first mode. The contribution of the higher modes is reduced because of 3D radiation, multiple generation sites, scattering, and a rapid decay in amplitude away from the ridge.
\end{abstract}

\section{Introduction}

The local generation of tidal internal waves (internal tides) at supercritical topography such as shelf edges and ocean ridges may be affected by internal tides generated at remote sites located from tens to hundreds of kilometers away (Largier 1994; Simmons et al. 2004; Jan et al. 2008; Farmer et al. 2009; Kelly and Nash 2010; Buijsman et al. 2010a; Zilberman et al. 2011; Kelly et al. 2012; Buijsman et al. 2012a, hereafter referred to as BLK; Ponte and Cornuelle 2013; Kerry et al. 2013;

Corresponding author address: Maarten C. Buijsman, University of New Orleans, 2000 Lakeshore Drive, Science Building, New Orleans, LA 70148.

E-mail: mbuijsma@uno.edu
Klymak et al. 2013). The phase difference between the remotely generated internal tides and the local barotropic flow can either enhance or decrease the barotropicto-baroclinic energy conversion, compared to when remotely generated internal tides are absent. The phasing of the remotely generated waves can also affect the fraction of the converted energy that is locally dissipated (Kelly et al. 2012; BLK), and hence, how much of the baroclinic energy is able to radiate away from its source. These radiated waves eventually cascade to smaller scales, contributing to a mixing of water mass properties (Munk and Wunsch 1998).

The Luzon Strait, between Taiwan and the Philippines, features two parallel north-south-oriented ridges, 60-100 km apart (Fig. 1), where internal waves radiated by either ridge strongly affect the conversion and 

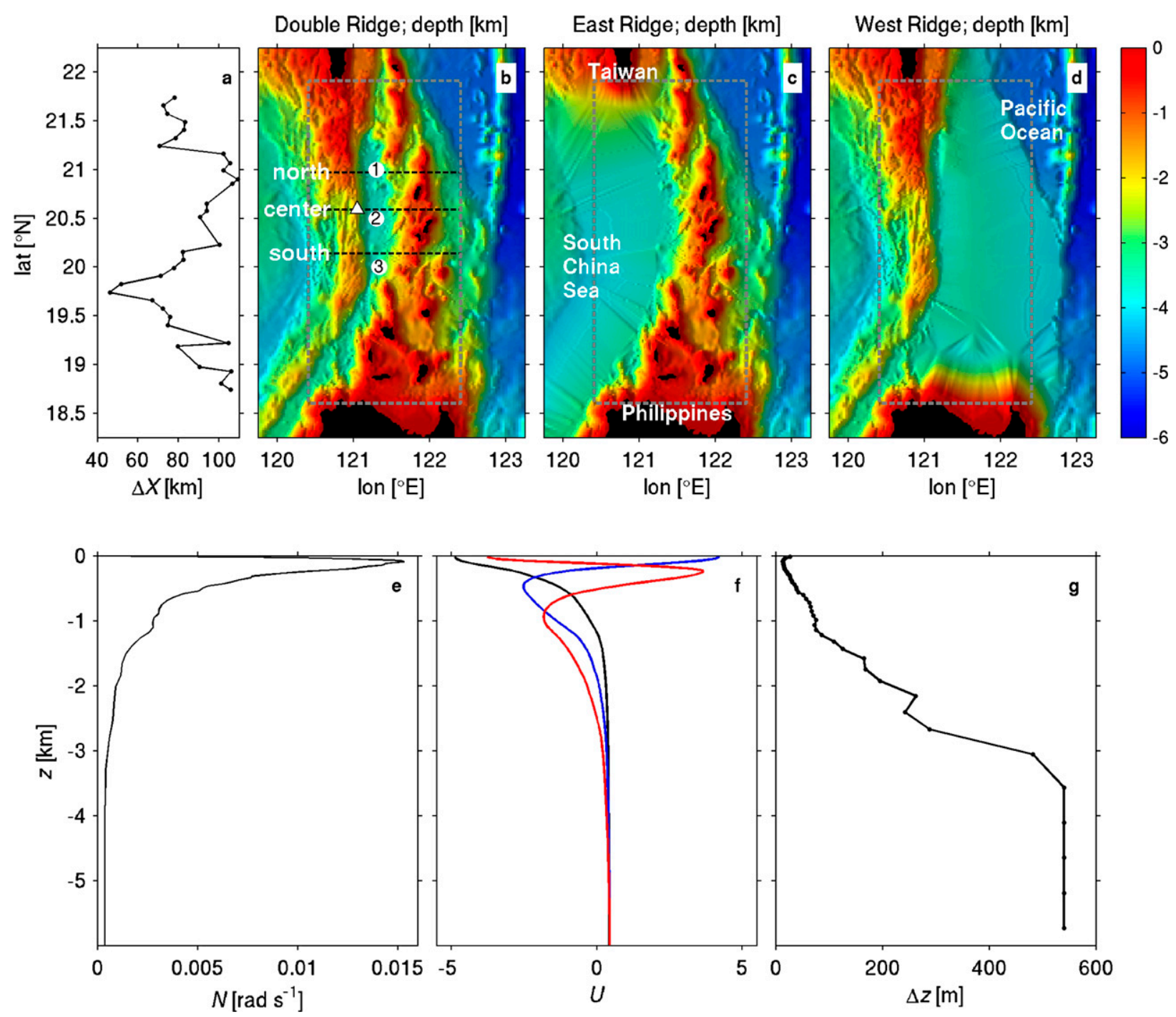

FIG. 1. (a) Zonal ridge separation distance between the western Hengchun and the eastern Lanyu ridges. Bathymetry in the Luzon Strait for the (b) double-ridge case, (c) single-east ridge case, and (d) single-west ridge case. The gray dashed box bounds the area where the grid spacing is constant with $\Delta x \approx \Delta y \approx 2 \mathrm{~km}$. The numbers in circles are PIES stations north (1), center (2), and south (3). The black and white triangle marks station N2. The black dashed lines are transects used for 2D modeling. Superposed on the coloring is a shaded relief with light (dark) shading for steep west (east)-facing slopes. (e) The buoyancy frequency $N$. (f) The first three semidiurnal eigenvectors $\mathcal{U}$. (g) The vertical grid size $\Delta z$.

dissipation at the opposing ridge. The local wave generation may also be modified by remote internal waves generated at the Mariana Island Arc (Kerry et al. 2013), which is not considered in our analysis. The strait is well known for its strong generation of nonlinear internal waves or solitons that propagate westward into the northern South China Sea (Ramp et al. 2004; Zhao and Alford 2006; Li and Farmer 2011). Recently, the interaction between the ridges has become the focus of attention. Observations by Alford et al. (2011), threedimensional (3D) modeling by Alford et al. (2011) and Jan et al. (2012), and two-dimensional (2D) modeling by
BLK and Klymak et al. (2013) reveal that when semidiurnal tides dominate, the conversion, flux divergence, and dissipation are enhanced relative to when diurnal tides dominate. This increase is most dramatic for the simulated dissipation rate, which doubles when semidiurnal tides dominate (BLK). In analytical and numerical 2D simulations by Farmer et al. (2009), Echeverri and Peacock (2010), BLK, and Klymak et al. (2013), it is shown that the internal wave fields are in phase and the conversion is enhanced when beams emitted from the opposing ridges superpose after one surface reflection during semidiurnal tides. The role of the beams in the 
TABLE 1. Overview of all model cases. Abbreviations lo and hi refer to low and high resolution, respectively.

\begin{tabular}{cl}
\hline \hline Case ID & \multicolumn{1}{c}{ Characteristics } \\
\hline $3 \mathrm{D}_{\mathrm{lo}}$ & $3 \mathrm{D} ;$ entire Luzon Strait \\
& $\Delta x \approx \Delta y \approx 2 \mathrm{~km}, 50 \mathrm{WKB}$ stretched layers \\
& Cases: semidiurnal and diurnal tides; double ridge, single east ridge, and single west ridge \\
$2 \mathrm{D}_{\mathrm{lo}}$ & $2 \mathrm{D} ;$ three zonal transects at $20.14^{\circ}, 20.59^{\circ}$, and $20.97^{\circ} \mathrm{N}$ \\
& $\Delta x=2 \mathrm{~km}, 50 \mathrm{WKB}$ stretched layers (same as $3 \mathrm{Dlo})$ \\
& Cases: semidiurnal and diurnal tides; double ridge, single east ridge, and single west ridge \\
$2 \mathrm{D}_{\mathrm{hi}}$ & $2 \mathrm{D} ;$ zonal transect at $20.59^{\circ} \mathrm{N}(\mathrm{BLK})$ \\
& $\Delta x=100 \mathrm{~m}, \Delta z=10 \mathrm{~m}$ \\
& Cases: diurnal and semidiurnal tides; double ridge, single east ridge, and single west ridge \\
\hline
\end{tabular}

resonance suggests that higher vertical modes may be important. Vlasenko et al. (2010) show with analytical 2D and numerical 3D simulations that the resonant interaction between the west and the east ridges enhances the generation of second-mode waves by the west ridge.

If the double ridges could be approximated as a series of $2 \mathrm{D}$ ridges forced by a cross-ridge velocity, semianalytical theories (Klymak et al. 2013) could be used to predict internal tide generation and dissipation. However, in the 3D topography of the Luzon Strait, the resonances may be affected by nonuniform wave generation along the ridges and oblique wave radiation, rather than simply cross-ridge radiation. The 3D aspects of the resonance may be reflected in the semidiurnal clockwise baroclinic flux gyre that forms in the $3.6-\mathrm{km}$ deep basin in between the ridges as observed in model simulations (Jan et al. 2008; Alford et al. 2011; Wang 2012). This circular feature is a manifestation of a horizontal standing internal wave caused by opposing wave sources (Nash et al. 2006; Martini et al. 2007). Similar standing waves, also referred to as basin modes or Poincaré waves, are simulated in enclosed lakes or basins (Csanady 1967; Buijsman et al. 2012b). In addition to the width, the resonance of these basin modes is also governed by the length of the basin or the along-ridge distance in the case of the Luzon Strait. It is yet unclear if and how the along-ridge distance affects the resonance in the strait.

This discussion raises several questions to be addressed in this study: 1) How are the physical processes of internal tide generation and dissipation affected by the 3D topography? 2) How does the double-ridge internal tide interference vary in the along-ridge direction in the Luzon Strait? 3) What baroclinic vertical modes cause this interference? 4) Is the standing wave a 2D phenomenon, which is primarily sensitive to the ridge heights and spacing, or is it a $3 \mathrm{D}$ phenomenon, which is also sensitive to the ridge lengths; that is, do resonant basin modes exist?

We address these questions using realistic $2 \mathrm{D}$ and $3 \mathrm{D}$ models. As in the 2D simulations of BLK, the resonance is investigated by omitting the east or west ridge. The model setup is further explained in the methodology section. In the results section, we diagnose the model output with the baroclinic energy equation for vertical modes. We elaborate on the differences in resonance between the 2D and 3D simulations in the discussion section. Idealized 3D model experiments are employed to enhance the understanding of the resonance.

\section{Methodology}

\section{a. Model setup}

\section{1) ReAlistic 3 D CASES}

The Massachusetts Institute of Technology General Circulation Model (MITgcm) (Marshall et al. 1997) is used in 3D and 2D configurations (Table 1). The eastwest (north-south) length of the 3D model domain is about $1400 \mathrm{~km}(750 \mathrm{~km})$. The area of interest, the Luzon Strait, is located in the center of the domain (Fig. 1b). The simulations have a horizontal resolution of $\sim 2 \mathrm{~km} \times$ $2 \mathrm{~km}$ in the domain center. Away from the center, the horizontal grid is telescoped to reach a maximum of $10.5 \mathrm{~km}$ at the model boundaries. The realistic 3D models have 50 vertical layers that are Wentzel-KramersBrillouin (WKB; Althaus et al. 2003) stretched above $z=-3.5 \mathrm{~km}$ (Fig. 1g) to better resolve the higher modes in the thermocline. The model features a subgrid-scale scheme that computes vertical viscosities and diffusivities above background values of $10^{-5} \mathrm{~m}^{2} \mathrm{~s}^{-1}$ by Thorpe sorting unstable density profiles (Klymak and Legg 2010). The horizontal viscosity and diffusivity are $10^{-2} \mathrm{~m}^{2} \mathrm{~s}^{-1}$ and $10^{-4} \mathrm{~m}^{2} \mathrm{~s}^{-1}$ and are constant in time. The quadratic bottom drag is set to 0.0025 . Because of the coarse vertical and horizontal resolution, the subgridscale mixing scheme does not function optimally, in particular at the deeper west ridge, where the vertical grid size is of the same order of magnitude as the overturns $[O(100 \mathrm{~m})]$.

The model uses realistic topography merged from highresolution gridded multibeam data with a resolution of 
$\sim 300 \mathrm{~m}$ and 30-arc second resolution global topography/ bathymetry grid (SRTM30_PLUS) data from the Smith and Sandwell database with a resolution of $\sim 1 \mathrm{~km}$ (Smith and Sandwell 1997). The density stratification in Fig. 1e is derived from temperature and salinity data collected in between the ridges (Alford et al. 2011; BLK). In the model, the density is only a linear function of temperature. The tidal forcing at the east, west, north, and south model boundaries composes 6-day time series of zonal and meridional barotropic velocities constructed from amplitudes and phases of eight tidal frequencies. The amplitudes and phases are extracted from the Ocean Topography Experiment (TOPEX)/Poseidon Global Inverse Solution 7.2 (TPXO7.2) (Egbert et al. 1994) at the location of the model boundaries. To allow for the inward propagation of the tidal barotropic waves while damping the outward-propagating baroclinic waves, the interior velocity fields are quadratically nudged following Lavelle and Thacker (2008) to the barotropic tidal velocities over 15 cells in from the boundaries. The interior temperature is nudged to a time-invariant temperature profile at the boundaries. In a sensitivity test, we find that the effect of wave reflections is minimized for a nudging time scale of $5400 \mathrm{~s}$. The largescale baroclinic energy flux patterns in our solutions are similar to these in modeling studies by Jan et al. (2008), Alford et al. (2011), and Wang (2012), which feature different boundary conditions and boundaries in different places, suggesting that the simulated large-scale flux patterns are not significantly affected by boundary reflections.

Six cases are run with the $3 \mathrm{D}$ model. We run the model for three bathymetry configurations: doubleridge, single-east ridge, and single-west ridge cases (Figs. 1b-d) and for two 6-day time periods in 2010 during which either semidiurnal or diurnal tides dominate. During the first period from 24 to 30 August, the semidiurnal (diurnal) tides are spring (neap). During the second period from 30 August to 5 September, the diurnal (semidiurnal) tides are spring (neap). These spring-neap cycles are visible in the 16-day time series of simulated zonal barotropic velocities at the east ridge in Fig. 8a of BLK. The 6-day duration allows for mode 18 to cross the $90-\mathrm{km}$ ridge separation distance. The last 2 days used for the analysis correspond to two 24-h stations N2a (28 August) and N2b (3-4 September) at the west ridge (white triangle in Fig. 1b) as part of the 2010 pilot of the Internal Waves in Straits Experiment (IWISE) (Alford et al. 2011). The observed subtidal surface velocities at these stations are northward, suggesting the presence of the Kuroshio between the east and west ridges (Alford et al. 2011).

\section{2) REAListic 2 D CASES}

The 3D model results are compared with low-resolution 2D simulations at three zonal transects: south at $20.14^{\circ} \mathrm{N}$, center at $20.59^{\circ} \mathrm{N}$, and north at $20.97^{\circ} \mathrm{N}$ (Fig. 1b; Figs. 2a-c; Table 1) and with the high-resolution 2D simulations by BLK at transect center, in order to isolate the influence of the 3D topography and/or 3D resonance on the behavior observed in the 3D simulations. The low-resolution 2D simulations are run for the same time periods and feature the same topography (Fig. 2), stratification, and horizontal and vertical resolution as in the 3D simulations and are forced in a similar way as the high-resolution 2D simulations described in BLK. The boundary forcing uses TPXO transports extracted in between the ridges at the same latitude as the transect. Hence, the zonal transports are spatially constant along the transect.

\section{b. Baroclinic energy equation and analysis}

In a similar approach to Buijsman et al. (2010b) and Kelly et al. (2012), we separate the velocity and pressure fields into semidiurnal or diurnal frequencies by harmonic analysis over the last 2.1 days of the simulations and map them to vertical modes. The $\mathrm{M}_{2}$ and $\mathrm{K}_{1}$ frequencies are the largest tidal constituents (Zhao and Alford 2006). The $\mathrm{M}_{2}\left(\mathrm{~K}_{1}\right)$ frequency is exclusively fitted to the velocity and density fields of the simulation during which semidiurnal (diurnal) tides dominate at station $\mathrm{N} 2 \mathrm{a}(\mathrm{N} 2 \mathrm{~b})$. The 2.1-day duration is long enough to separate the $\mathrm{M}_{2}$ from the $\mathrm{K}_{1}$ frequencies according to the Rayleigh criterion. The semidiurnal (diurnal) harmonic constants represent a mix of all four semidiurnal (diurnal) tidal constituents used in the model forcing because they cannot be effectively separated over such a short time period. As a consequence of the bandwidth of the fits, the amplitudes capture the variability of the spring-neap cycle for each of the diurnal and semidiurnal frequency bands. The single-frequency semidiurnal and diurnal harmonic fits explain about $84 \%$ and $83 \%$ of the variance of the simulated barotropic velocities, respectively.

For a depth-varying stratification $N(z)$, we solve the Sturm-Liouville eigenvalue problem for either semidiurnal or diurnal frequencies in each cell point $(x, y)$ to obtain the structure functions for modes $n=1, \ldots, 10$ for the vertical velocity $\mathcal{W}_{n}(x, y, z)$ and the horizontal velocity $\mathcal{U}_{n}(x, y, z) \sim \partial \mathcal{W}(x, y, z) / \partial z$ (Fig. 1f). The model resolution limits the number of vertical modes resolved at the supercritical ridges. Hence, we limit our analysis to 10 modes, which is adequate because the resonance is dominated by the low modes. Complex harmonic fits of the horizontal velocity $\mathbf{u}=(u, v)$ and pressure can be expressed as 

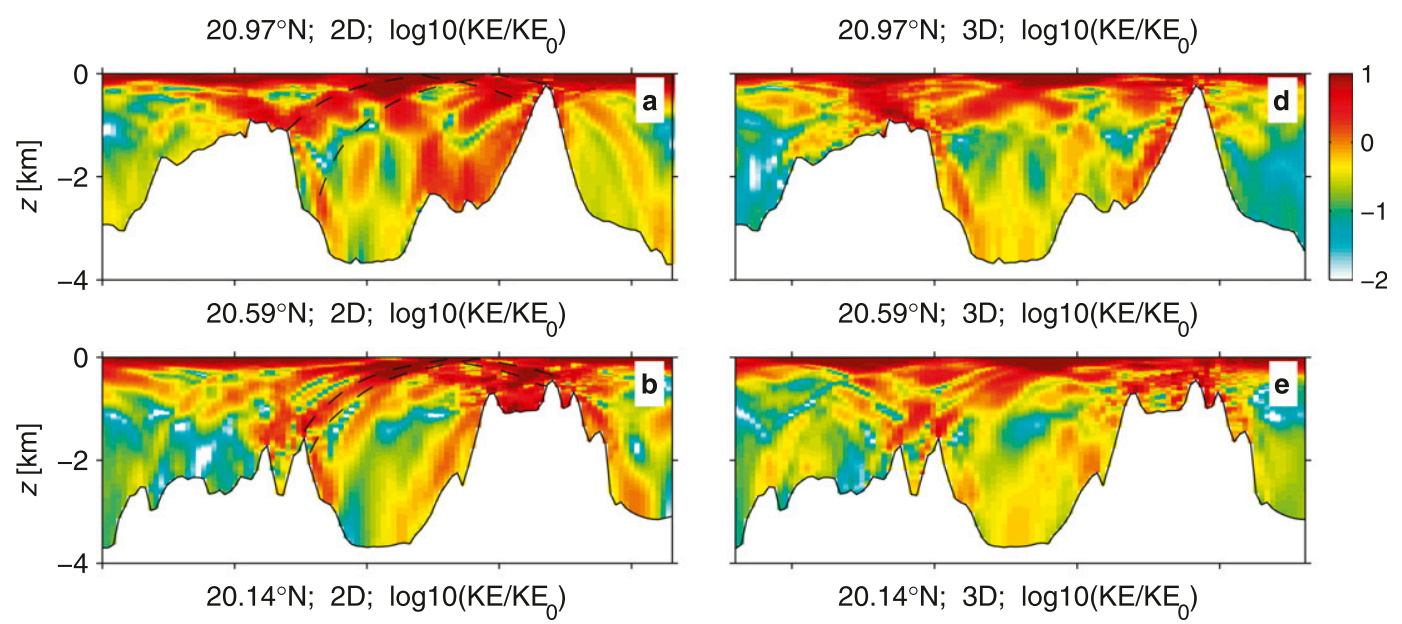

$20.59^{\circ} \mathrm{N} ; 3 \mathrm{D} ; \log 10\left(\mathrm{KE} / \mathrm{KE}_{0}\right)$

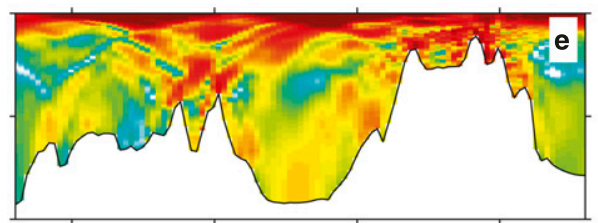

$20.14^{\circ} \mathrm{N} ; 3 \mathrm{D} ; \log 10\left(\mathrm{KE} / \mathrm{KE}_{0}\right)$
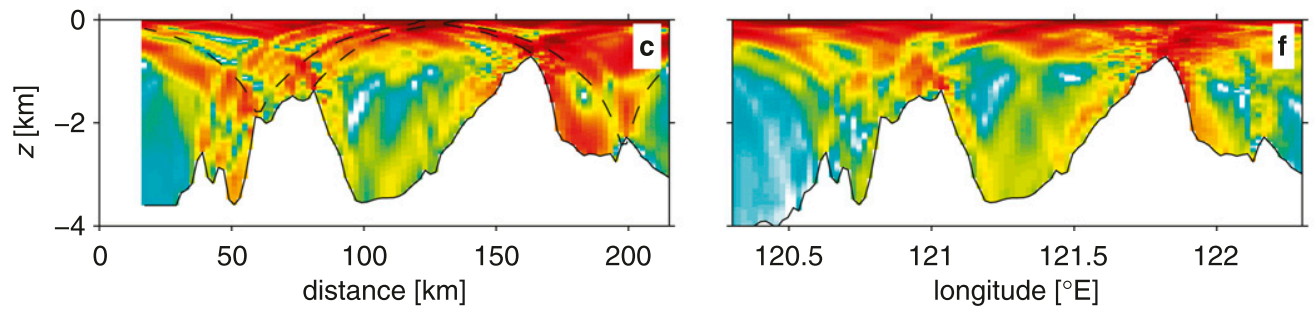

FIG. 2. Zonal transects of topography and semidiurnal tidal-mean baroclinic kinetic energy normalized by the transect-mean barotropic kinetic energy for the low-resolution $2 \mathrm{D}$ cases at (a) $20.97^{\circ}$, (b) $20.59^{\circ}$, and (c) $20.14^{\circ} \mathrm{N}$. (d)-(f) As in (a)-(c), but for the 3D cases. The black dashed lines are the theoretical internal wave beams.

$$
\begin{aligned}
& \mathbf{u}(x, y, z)=\sum_{n=0}^{10} \hat{\mathbf{u}}_{n}(x, y) \mathcal{U}_{n}(x, y, z) \quad \text { and } \\
& p(x, y, z)=\sum_{n=0}^{10} \hat{p}_{n}(x, y) \mathcal{U}_{n}(x, y, z),
\end{aligned}
$$

where $\hat{\mathbf{u}}_{n}$ and $\hat{p}_{n}$ are depth-independent complex constants for velocity and pressure.

The linearized tidal-mean depth-integrated kinetic and available potential energy equation for baroclinic vertical modes is (Kelly et al. 2012)

$$
\begin{aligned}
& \frac{\rho_{0} H}{4}\left[\left|\hat{\mathbf{u}}_{n}\right|^{2}+\left(1-\frac{f^{2}}{\omega^{2}}\right) \frac{\left|\hat{p}_{n}\right|^{2}}{\left(\rho_{0} c_{n}\right)^{2}}\right]_{t}+\frac{1}{2} \nabla \cdot\left(H \hat{\mathbf{u}}_{n}^{*} \hat{p}_{n}\right) \\
& =\sum_{m=0}^{10} C_{m n}
\end{aligned}
$$

where $c_{n}=\left(\omega^{2}-f^{2}\right) /\left(\omega k_{n}\right)$ is the group speed, $k_{n}$ is the horizontal wavenumber, $\rho_{0}$ is a reference density, $H$ is the water depth, $f$ is the Coriolis frequency, $\omega$ is a tidal frequency, the asterisk is the complex conjugate, and $m=0$ is the barotropic mode. The first term of (2) is the time derivative of the baroclinic horizontal kinetic and available potential energy, the second term is the energy flux divergence, and the third term is the conversion of energy from mode $m$ to mode $n$ :

$$
C_{m n}=\frac{1}{2} \int_{-H}^{0} \mathbf{u}_{m}^{*} \cdot \nabla p_{n}-\mathbf{u}_{n}^{*} \cdot \nabla p_{m} .
$$

The factor $1 / 2$ in (2) and (3) arises from time averaging over a tidal cycle. The tendency term is equal to zero when averaged over a tidal cycle. In a linear inviscid system, the tidal-mean balance is between the flux divergence and intermodal energy conversion. The source term is the energy conversion from the barotropic mode 0 to the baroclinic mode $n>0$ :

$$
C_{0 n}=-\frac{1}{2} \nabla H \cdot \mathbf{u}_{0}^{*} p_{n}(z=-H) .
$$

Shimizu (2011) and Kelly et al. (2012) have shown mathematically that flat bottom vertical modes can be applied to horizontally varying topography and stratification.

Although the model resolution is too coarse to correctly predict dissipation from overturns, the dissipation estimates still give insight into the resonance characteristics of the double ridge. The difference between the conversion and flux divergence for either the semidiurnal or diurnal constituent, summed over 10 modes, is defined as the diagnosed dissipation:

$$
D_{\text {diag }}=\sum_{n=1}^{10}\left[C_{0 n}-\frac{1}{2} \nabla \cdot\left(H \hat{\mathbf{u}}_{n}^{*} \hat{p}_{n}\right)\right]
$$




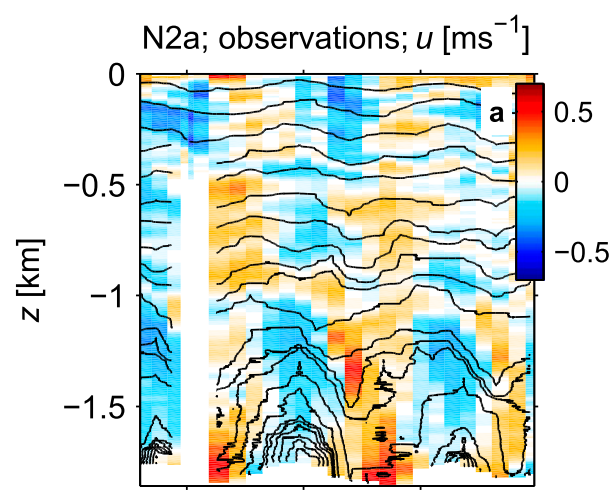

$239.2 \quad 239.6 \quad 240$

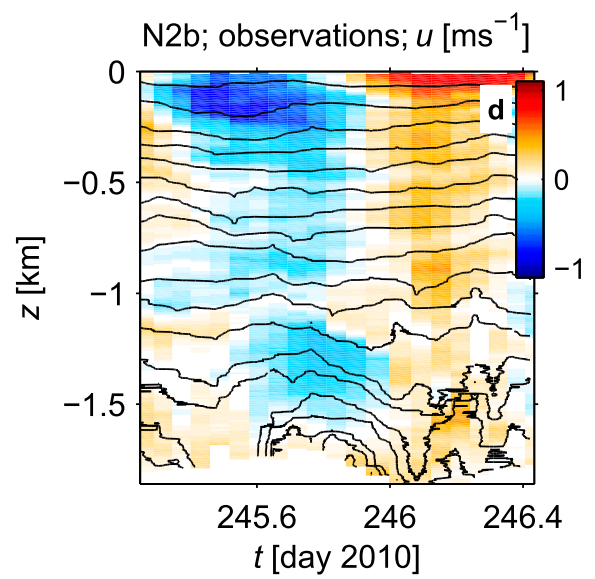

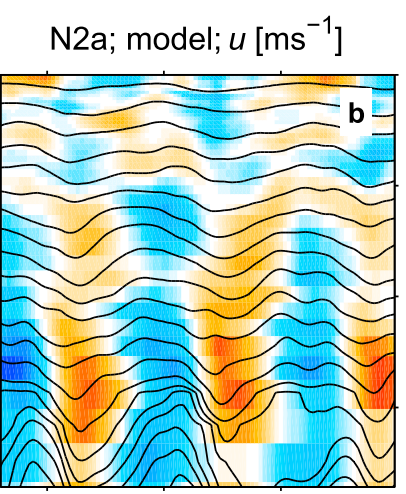

$239.2 \quad 239.6 \quad 240$

$\mathrm{N} 2 \mathrm{~b} ;$ model; $u\left[\mathrm{~ms}^{-1}\right]$

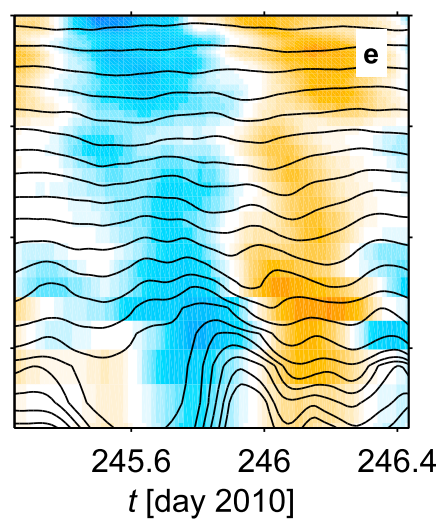

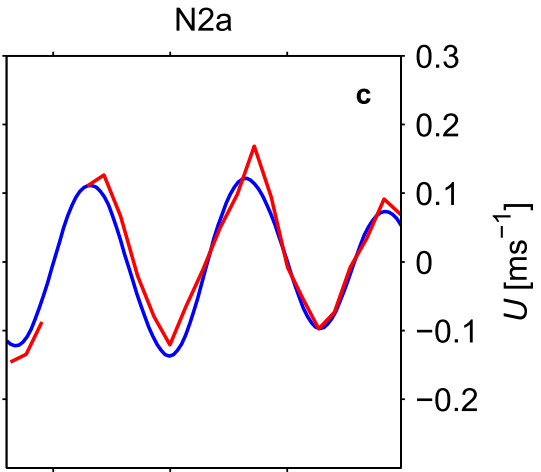

$239.2 \quad 239.6 \quad 240$

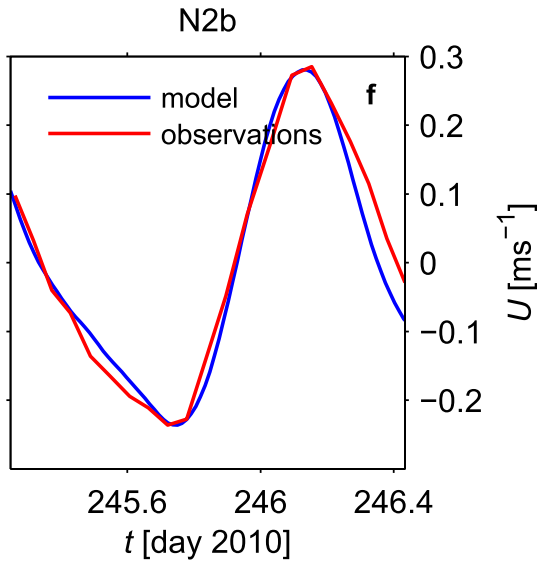

FIG. 3. (a) Observed and (b) simulated zonal velocities (colors) and density (contours), and (c) observed and simulated barotropic velocities for station N2a when semidiurnal tides are dominant. (d)-(f) As in (a)-(c), but for station N2b when diurnal tides are dominant. The simulations are from the $3 \mathrm{D}$ model. The bottom is at $-1800 \mathrm{~m}$. The density is contoured every $100 \mathrm{~m}$ for an ocean at rest. The depth-mean values are removed from the zonal velocities. Yeardays 239 and $245 \mathrm{refer}$ to $28 \mathrm{Aug}$ and 3 Sep 2010.

This estimate is imprecise because it ignores the modes $>10$, the advective and diffusion terms, and the diurnal contribution to the semidiurnal energy balance, and vice versa. The spatial patterns in the diagnosed dissipation are similar to the reported dissipation $D_{\text {rep }}$, which is directly computed from the vertical and horizontal velocity shear and bottom stresses (BLK), but their magnitudes differ within a factor of 2 .

Although the Luzon Strait is known to be a source of highly nonlinear internal waves (Ramp et al. 2004) and a site for strong turbulent lee waves near the ridge crests (Alford et al.2011), we will use linear vertical modes and the linear baroclinic energy equation. We show in the appendix that the time-mean nonlinear advection and dissipation terms of the nonlinear baroclinic energy equation are significant only for ridges shallower than $1000 \mathrm{~m}$, which cover about $20 \%$ of the surface area of the strait. Our linear approach is therefore valid for about $80 \%$ of the strait.

\section{Results}

\section{a. Model validation}

The 3D simulations are validated with observations mainly collected at the ridges, where baroclinic wave generation, energy fluxes, and dissipation are strong (2010 pilot stations), and in the trench between the ridges, where standing baroclinic waves are apparent pressure sensor-equipped inverted echo sounder (PIES) stations.

\section{1) 2010 PILOT STATIONS}

The predicted barotropic and baroclinic motions are compared to observations collected at nine 24-36-h stations and one multiday mooring as part of the IWISE 2010 pilot (Alford et al. 2011). Because the simulations only coincide with stations N2a and N2b, we first compare the unfiltered simulations with the observations at these stations (Fig. 3). In contrast to the high-resolution 2D simulations by BLK, the zonal barotropic velocities 
during N2a and N2b in Figs. $3 \mathrm{c}$ and $3 \mathrm{f}$ are correctly simulated with the 3D model. Similarly, there is a reasonable agreement between the observed and simulated velocities and isotherm oscillations during the predominantly semidiurnal (Figs. 3a,b) and diurnal (Figs. $3 \mathrm{~d}, \mathrm{e})$ periods. However, the model does not always correctly simulate the baroclinic waves. In the observations during N2a (Fig. 3a) there appears to be a secondmode wave at $z \approx-700 \mathrm{~m}$ and 239.6 days that is not visually present in the simulations (Fig. 3b). During the diurnal period, the model does not fully capture the strong baroclinic velocities in the upper $500 \mathrm{~m}$ in Figs. 3d and $3 \mathrm{e}$ that give rise to appreciable energy fluxes. The strong eastward and downslope bottom-intensified velocities (warm colors) and coinciding isopycnal depressions in Figs. 3a, 3b, 3d, and 3e are characteristics of arrested internal waves (or turbulent lee waves) (Legg and Klymak 2008; Klymak et al. 2010).

We do not run the simulations for a long enough duration to coincide with the other pilot stations. Hence, the harmonically fitted $\mathrm{M}_{2}$ and $\mathrm{K}_{1}$ barotropic velocity amplitudes of the observations are normalized with the TPXO $\mathrm{M}_{2}$ and $\mathrm{K}_{1}$ amplitudes and then multiplied by the TPXO $\mathrm{M}_{2}$ and $\mathrm{K}_{1}$ amplitudes that coincide with the N2a and $\mathrm{N} 2 \mathrm{~b}$ periods, respectively. Only stations with periods close to the diurnal or semidiurnal spring tide are shown. During both semidiurnal and diurnal tides, the model slightly underpredicts the observed major axis by a factor of 0.94 with a standard deviation of 0.08 at the stations along the northern line near $20.6^{\circ} \mathrm{N}$ and slightly overpredicts the major axis by a factor of $1.16 \pm 0.32$ at the stations along the southern line near $19.5^{\circ} \mathrm{N}$ (Figs. 4a,b).

We also compare the observed with the predicted mode- 1 pressure fluxes in Figs. 5a and 5b. The fluxes are scaled with the barotropic kinetic energy (Alford et al. 2011). Simulated mode-1 fluxes show similar patterns as the observed fluxes, with a mean direction difference of $21^{\circ} \pm 18^{\circ}$. Compared to the barotropic tidal ellipses, the magnitudes of the energy fluxes show considerable differences between the simulations and observations. On average the simulated semidiurnal (diurnal) mode- 1 fluxes, excluding station MPN (N2), are a factor of $0.98 \pm$ $0.62(0.91 \pm 0.28)$ smaller than the observations. Most notable are the discrepancies between the model and observations along the northern line, where the model overpredicts the semidiurnal fluxes at MPN by a factor 12 (Fig. 5a) and underpredicts the diurnal fluxes at N2 by a factor of 0.13 (Fig. 5b). The reasons for these discrepancies are not yet known, but they may be attributed to the short duration of the observations and/or the possible influence of mesoscale flow in the observations, which may advect the internal tides, and associated

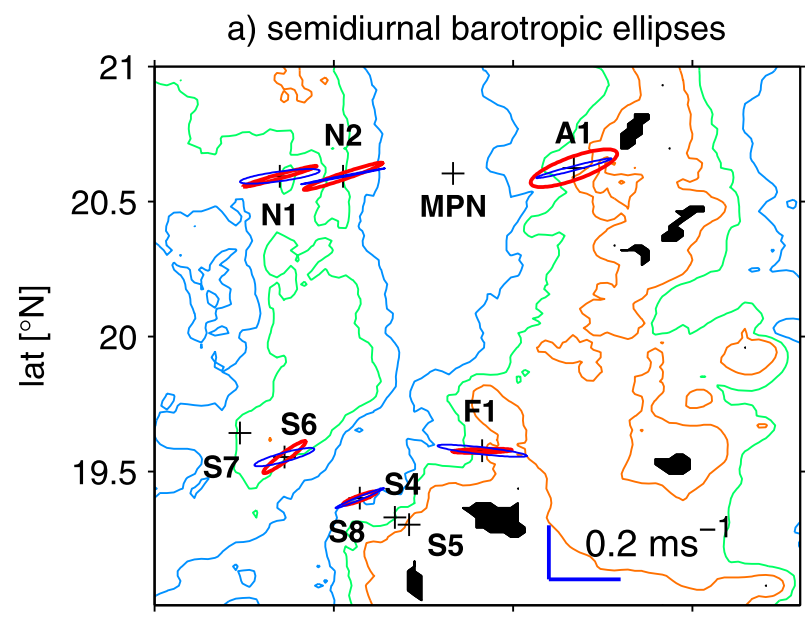

b) diurnal barotropic ellipses

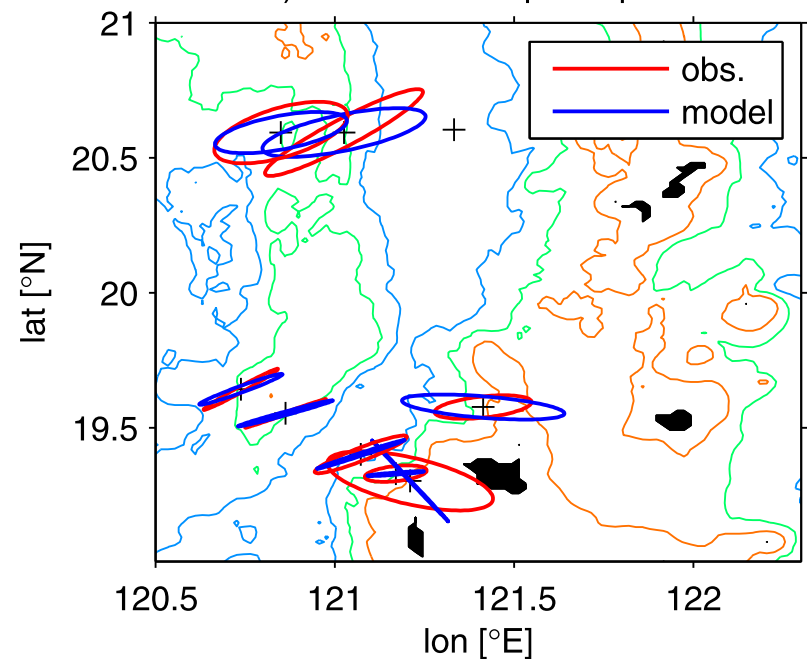

FIG. 4. Observed (red) and simulated (blue) scaled barotropic ellipses for (a) semidiurnal and (b) diurnal tides for selected stations. Bathymetry is contoured every $1000 \mathrm{~m}$.

spatially varying stratification, which may affect the internal tide generation and propagation (e.g., Rainville and Pinkel 2006; Kurapov et al. 2010; Jan et al. 2012).

Both the (semi)diurnal simulations and observations show a clockwise flux gyre around station MPN, which is an indication of a standing wave (Alford et al. 2011). The simulated semidiurnal mode-1 flux at MPN is larger than the observed flux. However, the simulated westward fluxes decrease north of MPN, suggesting that the flux pattern is offset to the north relative to the observations. The prediction of the semidiurnal clockwise flux gyre is further supported by additional observations in Fig. 1b of Alford et al. (2011) that show southward semidiurnal fluxes at several stations close to station A1.

The modal distribution at four selected stations, of which the agreement between simulations and observations is poorest at station $\mathrm{N} 2 \mathrm{~b}$ during diurnal tides, is 
a) semidiurnal mode 1 fluxes

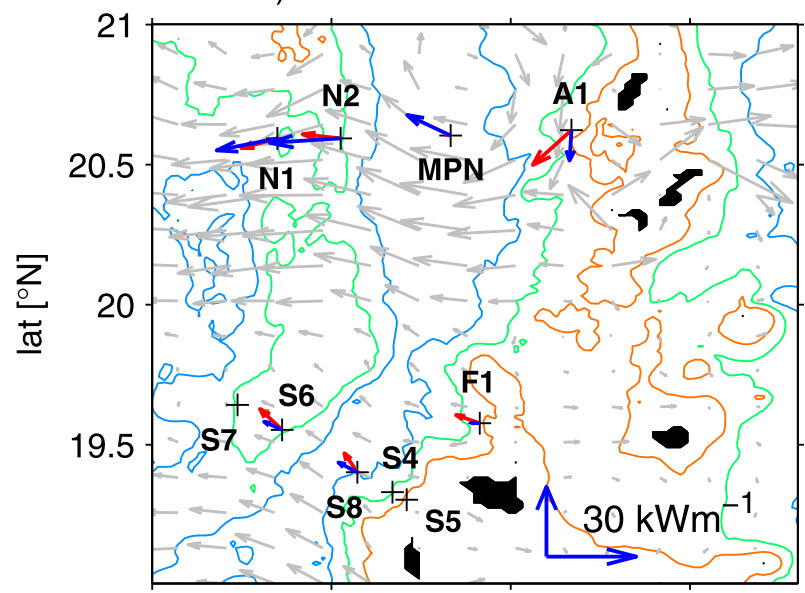

b) diurnal mode 1 fluxes

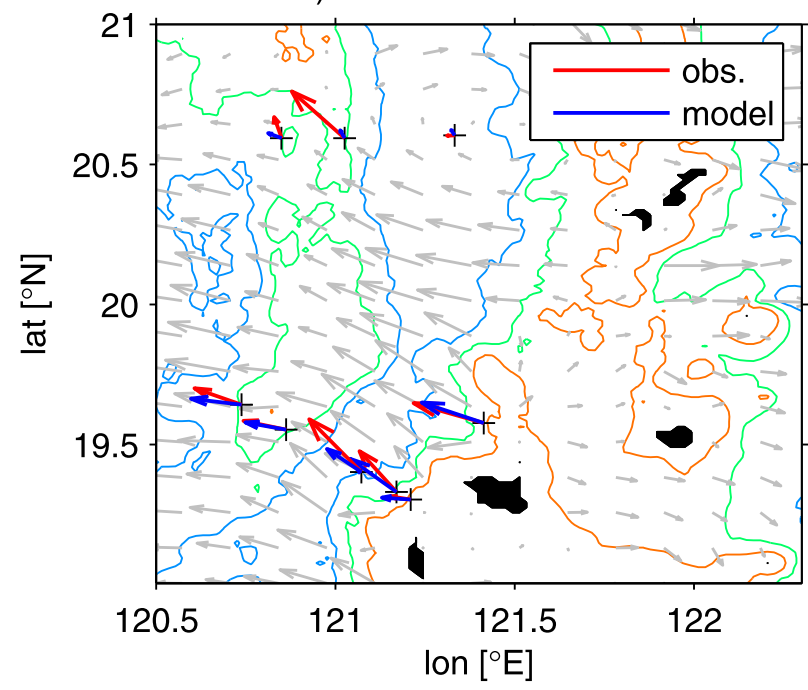

c) relative flux per mode

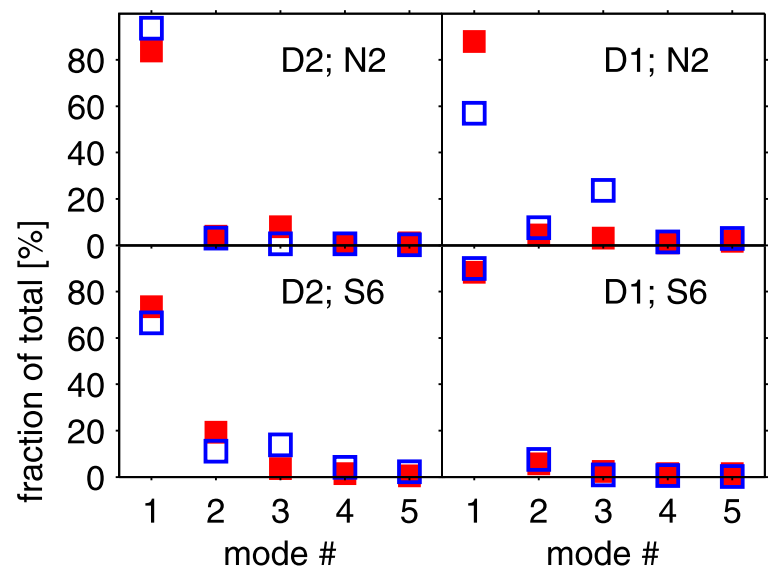

FIG. 5. Observed (red) and simulated (blue) scaled mode-1 fluxes for (a) semidiurnal and (b) diurnal tides for selected stations superposed on the simulated fluxes (gray). The fluxes at MPN are plotted, but they are small. Bathymetry is contoured every $1000 \mathrm{~m}$. (c) Observed (red) and simulated (blue) fluxes $|F|=\sqrt{F_{x}^{2}+F_{y}^{2}}$ per mode relative to the total for stations N2 and S6 for semidiurnal (D2) and diurnal (D1) tides. in Fig. 5c. Similar to the observations at most stations, the simulations have more than $80 \%$ of the total pressure flux in mode 1 , which is to be expected for tall supercritical ridges (St. Laurent et al. 2003). This agreement suggests that the relatively coarse model resolution has little effect on the low-mode energy fluxes. Similarly, the simulated mode- 1 energy fluxes compose $\sim 80 \%$ of the total energy flux when averaged over the Luzon Strait for semidiurnal and diurnal tides.

\section{2) PIES STATIONS}

PIES are bottom-mounted sensors that allow for the measurement of mode- 1 isotherm oscillations near the thermocline through acoustic pulses ( $\mathrm{Li}$ et al. 2009). Semidiurnal and diurnal amplitudes and phases are computed for a 1-day moving window for data from PIES north and south collected in the winter of 2010/11 and center and south collected in the summer of 2011 (numbers 1-3 in Fig. 1b). The sinusoids for the mean complex amplitudes are the solid lines in Fig. 6. The shading marks the spring-neap and subtidal variability. The simulated isopycnal oscillations $\zeta=b / N^{2}$, where buoyancy $b=-g \rho^{\prime} / \rho_{0}$ and $\rho^{\prime}$ is the perturbation density, have the largest amplitudes at $z=\sim 830 \mathrm{~m}$, used for the comparison (dashed lines). There is a fair agreement between the observations and simulations at stations south and center, where the first-mode waves are in phase (Figs. 6b,d). The simulated and observed waves at station north are out of phase with the waves at station south (Figs. 6a,c), suggesting the existence of a (semi) diurnal standing wave in the trench, in agreement with the modeled and observed flux gyres in Figs. 5a and 5b. However, the simulated semidiurnal (diurnal) wave at station north is less (more) out of phase with the simulated wave at station south when compared to the observations. The cause of these phase differences and the offset in the flux gyre during semidiurnal tides in Fig. 5a are not fully understood but may involve the mesoscale flow, not present in our simulations.

\section{b. The barotropic tide}

When the (semi)diurnal barotropic Kelvin wave enters the Luzon Strait from the Pacific Ocean (Jan et al. 2008), its pathway is affected by the double-ridge topography (Fig. 7). The largest velocities occur at the shallow crests of the central and southern sections of the east ridge and the northern section of the west ridge. At these locations internal wave generation and nonlinear effects such as dissipation (appendix) are large. The diurnal barotropic spring tide velocities (not shown) show similar patterns to those of the semidiurnal tide, but the diurnal amplitudes are about twice as large. The barotropic flow is steered away from shallow topography, such as west of the east 

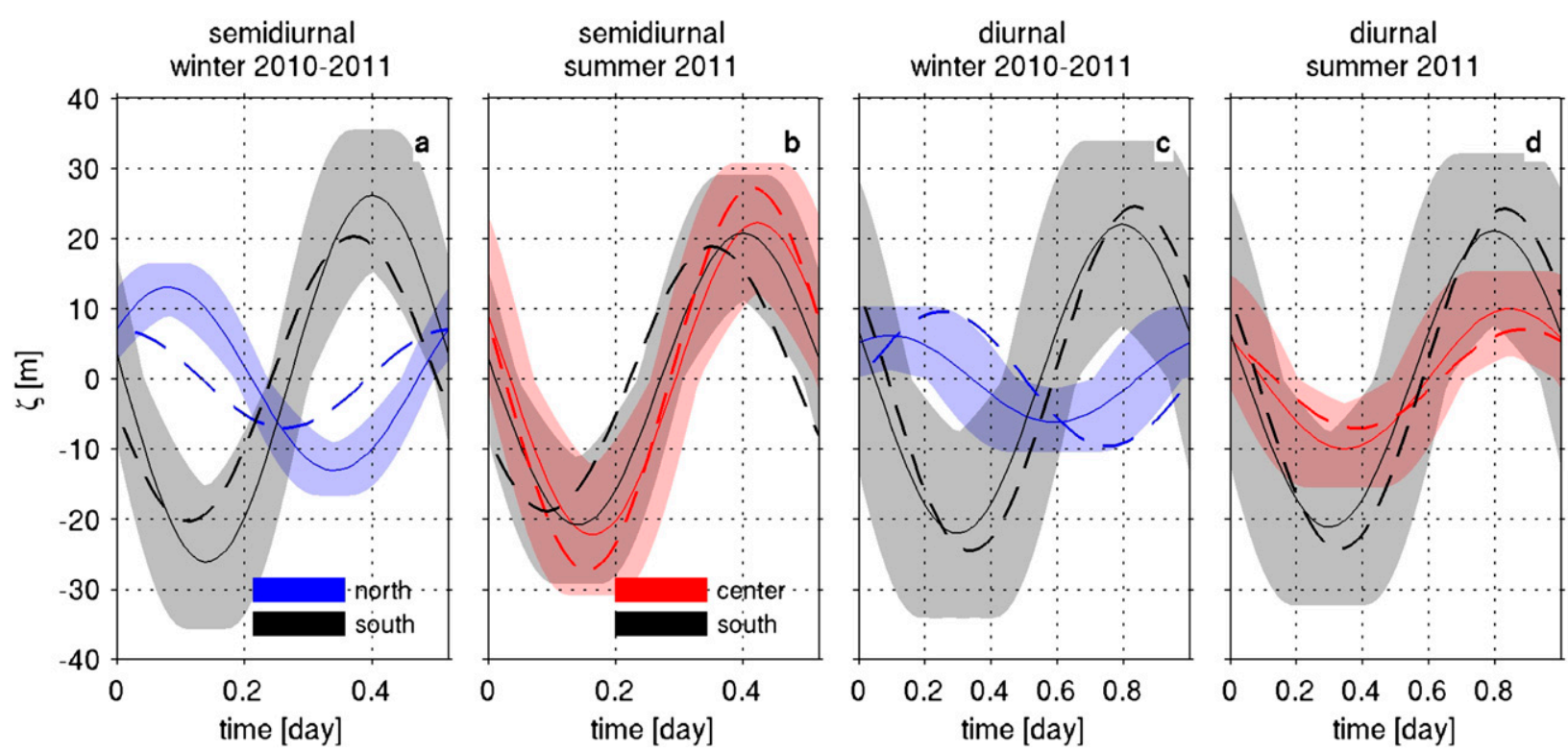

FIG. 6. Comparison between simulated (dashed lines) and observed (solid lines) thermocline isotherm oscillations at three PIES stations north (blue), center (red), and south (black) (see Fig. 1b for locations) for semidiurnal and diurnal tides. The solid lines are the mean oscillation of the PIES data and the shaded areas mark their variability over several months. (a),(c) The PIES stations north and south are for the winter 2010/11 and (b),(d) the stations center and south are for the summer 2011.

ridge near area I (Fig. 7), where the ellipses are oriented approximately parallel to isobaths. Earlier studies have identified similar blocking of the barotropic flow by topography in 3D (e.g, Holloway and Merrifield 1999; Dewey et al. 2005). As discussed later, this topographic blocking has a large effect on the 3D internal wave generation when compared to $2 \mathrm{D}$ simulations. The maximum velocities occur at the same time nearly everywhere in the Luzon Strait (Fig. 7); the phase differences are generally $<\left|30^{\circ}\right|$.

\section{c. Differences between semidiurnal and diurnal baroclinic energetics}

\section{1) FLuXES AND CONVERSION}

Spatial maps of conversion and fluxes illustrate the differences in semidiurnal and diurnal patterns (Fig. 8). The mode-1 fluxes are an order of magnitude smaller than the barotropic fluxes. The semidiurnal conversion of the barotropic and baroclinic modes to mode $1 C_{1}$ is largest at the ridge crests of the double ridge in the center of the strait between $19.9^{\circ}$ and $21.3^{\circ} \mathrm{N}$ (Fig. 8a). This conversion pattern gives rise to the large clockwise mode-1 flux gyre, with strong westward and weak eastward fluxes.

In contrast to the semidiurnal tides, the diurnal firstmode conversion and fluxes are largest in the southern half of the strait (Fig. 8c). Moreover, while the semidiurnal first-mode conversion is generally positive on the trench-facing slopes in the central strait between $19.9^{\circ}$ and $20.3^{\circ} \mathrm{N}$, the diurnal conversion has opposite signs on the trench slopes that face each other, implying that the bottom perturbation pressure of the first-mode waves generated at the west (east) ridge is out of phase with the barotropic downslope flow at the east (west) ridge.

In the Luzon Strait, $60 \%$ of the barotropic energy that is converted to baroclinic energy goes into mode 1 for both semidiurnal and diurnal tides, with the remainder contributing to higher modes and dissipation. Hence, the higher-mode conversion and fluxes are weaker than the first-mode conversion and fluxes (Figs. 8b,d). During semidiurnal tides, the ridges facilitate more low- to highmode scattering than during diurnal tides. For example, the conversion of mode 1 to higher modes between $19.5^{\circ}$ and $20.5^{\circ} \mathrm{N}$ near $120.75^{\circ} \mathrm{E}$ in Fig. 8a (cold colors) is mirrored in the generation of higher modes (warm colors and fluxes) in Fig. 8b.

\section{2) First-MODE STANDING WAVES}

The semidiurnal clockwise flux gyre in the central strait, found in other Luzon Strait studies, is found here as well. It has high kinetic energy at its core (Fig. 9a) and high available potential energy near the basin walls, separated by a quarter wavelength from the kinetic energy maximum (Fig. 9b), characteristics of a baroclinic Poincare wave that is first mode in the vertical, radial, and azimuthal directions (Csanady 1967). The amphidromic 


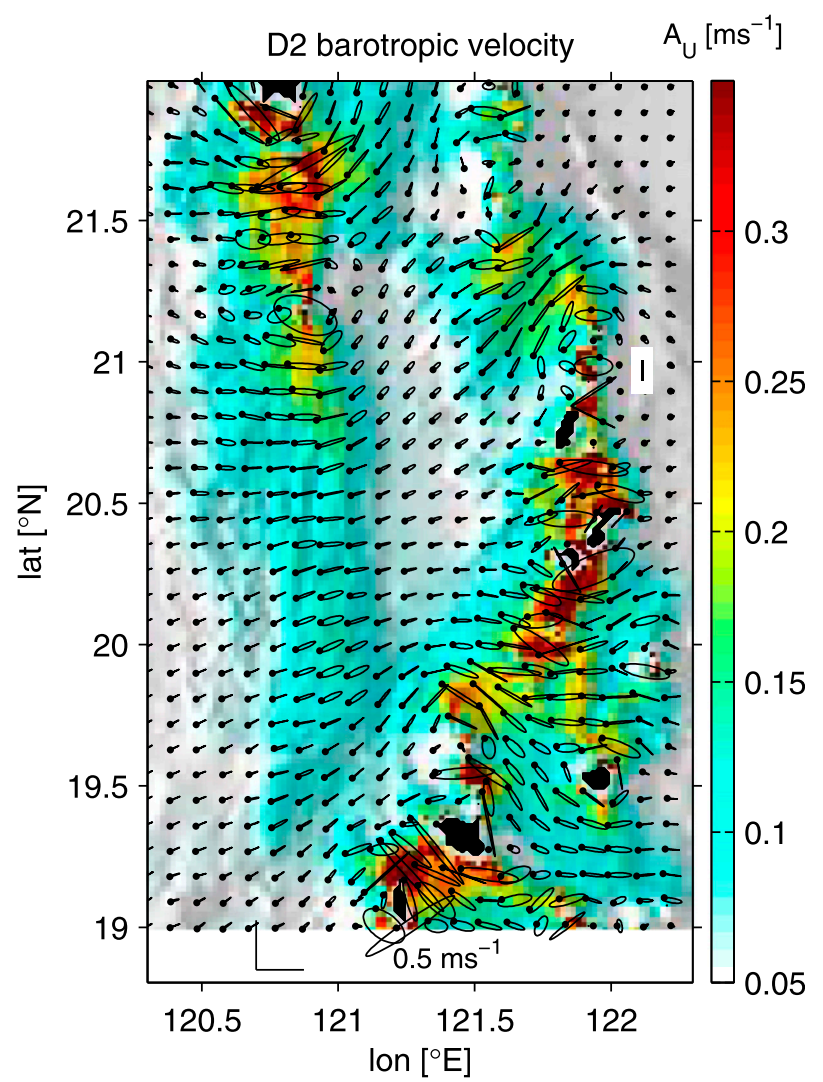

FIG. 7. Barotropic tidal ellipses and major axes amplitudes (colors) for D2 tides for the double-ridge simulations. The dots indicate time is zero to show how the phase of the barotropic tide changes.

point coincides with the maximum in the kinetic energy. The mismatch between the simulated and observed isotherm oscillations at the northernmost PIES station in Fig. 6a may be because it is close to the amphidromic point in Fig. 9c, so that small differences in location relative to the amphidromic point can lead to large differences in phase and amplitude. While the isotherms at opposing ends from the amphidromic point are always out of phase, similar to the PIES data, the first-mode bottom (and surface) velocity vectors rotate clockwise and are in phase everywhere in the trench. This standing wave modified by rotation is not a baroclinic Kelvin wave, which would propagate with the wall to its right and have the largest kinetic and potential energy near the wall (in the Northern Hemisphere).

In contrast, while the diurnal first-mode wave has large kinetic energy in the trench (Fig. 9d), it lacks high available potential energy on the walls to the west and east (Fig. 9e) and a clear amphidromic point in the center (Fig. 9f). While the ridge separation distance of about $90 \mathrm{~km}$ permits an east-west oscillating semidiurnal first-mode wave with a wavelength of $\sim 150 \mathrm{~km}$, it is too short to allow for the east-west oscillation of a diurnal first-mode wave of $\sim 350 \mathrm{~km}$. Instead, the north-south $180^{\circ}$ phase difference in Figs. $6 \mathrm{c}$ and $9 \mathrm{f}$ and the elevated levels of available potential energy to the north and south of the center with high kinetic energy suggest the presence of a weak diurnal standing wave that is oscillating along the north-south axis.

\section{d. Double-ridge internal wave amplification}

Having considered the energetics of the standing waves in the $3 \mathrm{D}$ double-ridge case, we now compute the amplification $\Psi$ (BLK) of the conversion, flux divergence, and dissipation in the double ridge relative to the single-ridge cases and compare with $2 \mathrm{D}$ results. The amplification, for example, for conversion reads

$$
\Psi_{C}=\frac{C_{\mathrm{DR}}-\left(C_{\mathrm{WR}}+C_{\mathrm{ER}}\right)}{C_{\mathrm{WR}}+C_{\mathrm{ER}}},
$$

where subscripts WR, ER, and DR refer to the single west-ridge, single east-ridge, and double-ridge cases, respectively. The time-mean energy terms are zonally integrated and meridionally averaged to $0.15^{\circ}$ bins for the double- and single-ridge cases of the realistic 2D and 3D simulations for semidiurnal and diurnal tides (Fig. 10). The amplification and energy terms integrated over the central strait are listed in Table 2.

The amplification of the conversion in the highresolution $2 \mathrm{D}$ case and the low-resolution $2 \mathrm{D}$ case at the central transect at $20.59^{\circ} \mathrm{N}$ is similar during semidiurnal tides (Fig. 10a). This implies that, for the cases studied, the resolution has a limited effect on the amplification of the conversion. This justifies the use of coarse resolution for the 3D simulations, which is computationally less expensive. The difference between the high- and low-resolution 2D simulations is larger for the dissipation (Fig. 10e) because breaking lee waves are not well resolved in the coarse-resolution model.

As for the 2D simulations of BLK, the amplification of the conversion, flux divergence, and reported and diagnosed dissipation during semidiurnal tides is generally larger than during diurnal tides for all simulations, in particular in the central strait between $20^{\circ}$ and $21.2^{\circ} \mathrm{N}$ (Table 2), where the ridges have a separation distance of about $90 \mathrm{~km}$ (Fig. 1a) and where the clockwise flux gyre occurs. A striking difference, and the main result of this study, is that the semidiurnal amplification of the conversion and flux divergence is significantly larger in the 3D than the 2D simulations (Fig. 10a).

This semidiurnal amplification in the central strait is largely due to mode 1 in the $2 \mathrm{D}$ and $3 \mathrm{D}$ simulations (Figs. 10a,b). The semidiurnal amplification of the barotropic energy conversion to the second and higher modes 


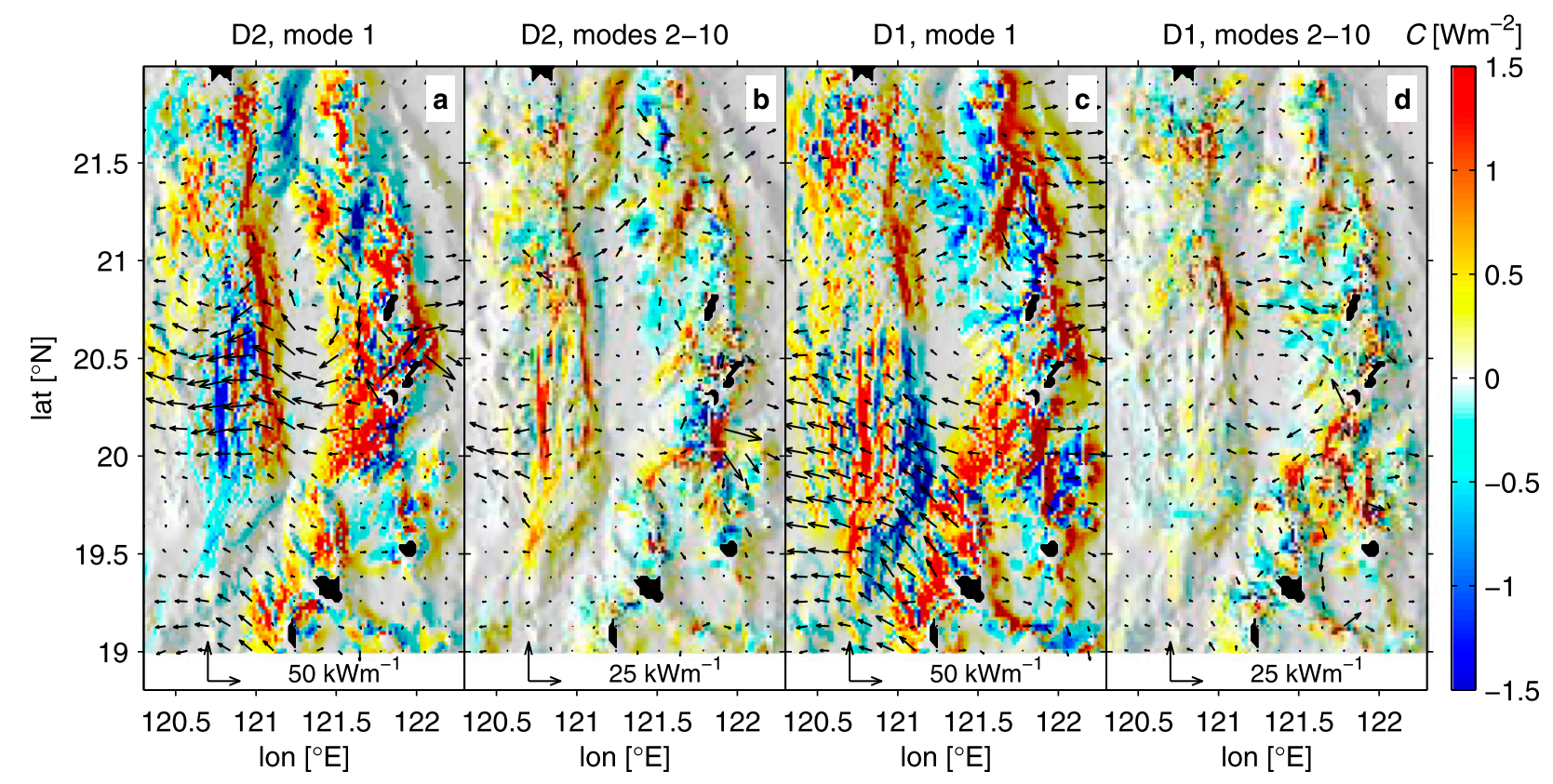

FIG. 8. The semidiurnal time-mean and depth-integrated conversion and fluxes for (a) mode 1 and (b) the sum of modes 2-10. (c),(d) As in (a),(b), but for diurnal (i.e., D1) tides.

is mainly positive, but it features spatial variability at smaller spatial scales than the first-mode amplification and is larger than the first-mode amplification to the south (north) of $20.2^{\circ} \mathrm{N}\left(21.2^{\circ} \mathrm{N}\right)$ in Fig. 10c. In the central strait, the amplification of the diurnal conversion to the first mode is the most negative (Fig. 10b), but this is somewhat countered by the positive amplification of the conversion to higher modes (Fig. 10c).

Both the diagnosed and reported dissipation rates are large at the supercritical ridge crests where the barotropic velocities are large (Fig. 7). Here, barotropic energy is transferred to breaking lee waves (BLK). Although the central strait-averaged diagnosed and reported dissipation rates differ (Table 2), due to the coarse 3D model resolution, their amplification magnitudes and patterns are similar in Fig. 10e. This gives us some confidence that, similar to the conversion and flux divergence, the dissipation is also enhanced in the central strait when semidiurnal tides dominate.

\section{Discussion}

The major result of the previous section is the much larger double-ridge amplification of the semidiurnal conversion, flux divergence, and dissipation in the 3D simulations compared to 2D simulations (Fig. 10; Table 2) in the central Luzon Strait between $19.9^{\circ}$ and $21.2^{\circ} \mathrm{N}$. This difference in amplification occurs despite the similar mode- 1 standing wave seen in the trench between the ridges in this region in both $2 \mathrm{D}$ and $3 \mathrm{D}$ simulations.
In this discussion section, we investigate the $3 \mathrm{D}$ influences on the resonance including (i) if the large-scale dimensions of the 3D basin are resonant to basin modes that enhance the conversion and dissipation relative to 2D simulations; (ii) if the 3D internal wave generation due to the nonuniform 3D bathymetry causes a stronger amplification in the 3D simulations; and (iii) why most of the resonance occurs in mode 1 in the realistic simulations.

\section{a. Basin modes}

Circular or elliptic lakes and ocean basins can be resonant to certain Kelvin or Poincaré modes (Csanady 1967; Antenucci and Imberger 2001), depending on basin dimensions, stratification, and forcing frequency. Csanady (1967) and Antenucci and Imberger (2001) derived dispersion relations for circular and elliptic twolayer basins, respectively. The central basin in the Luzon Strait has a north-south distance of $\Delta Y \approx 150 \mathrm{~km}$, a mean separation distance of $\Delta X \approx 90 \mathrm{~km}$, and a mean depth of $2.5 \mathrm{~km}$. For a two-layer stratification, the nonrotating phase speed $c=3.36 \mathrm{~m} \mathrm{~s}^{-1}$ and the wavelength $\lambda=150 \mathrm{~km}$. Hence, $\Delta X / \lambda \approx 0.6$ and $\Delta Y / \lambda \approx 1$ for the central basin. Following Antenucci and Imberger (2001) and Buijsman et al. (2012b), we find the ratio between the eigenfrequency and the $M_{2}$ frequency $\omega_{e} / \omega_{2}=1.1$, which is close to resonance for vertical, radial, and azimuthal first-mode Poincaré waves. For a greater depth of $3 \mathrm{~km}$, the elliptic basin becomes slightly less resonant $\left(\omega_{e} / \omega_{2}=1.14\right)$. For elliptic basins close to resonance, the 

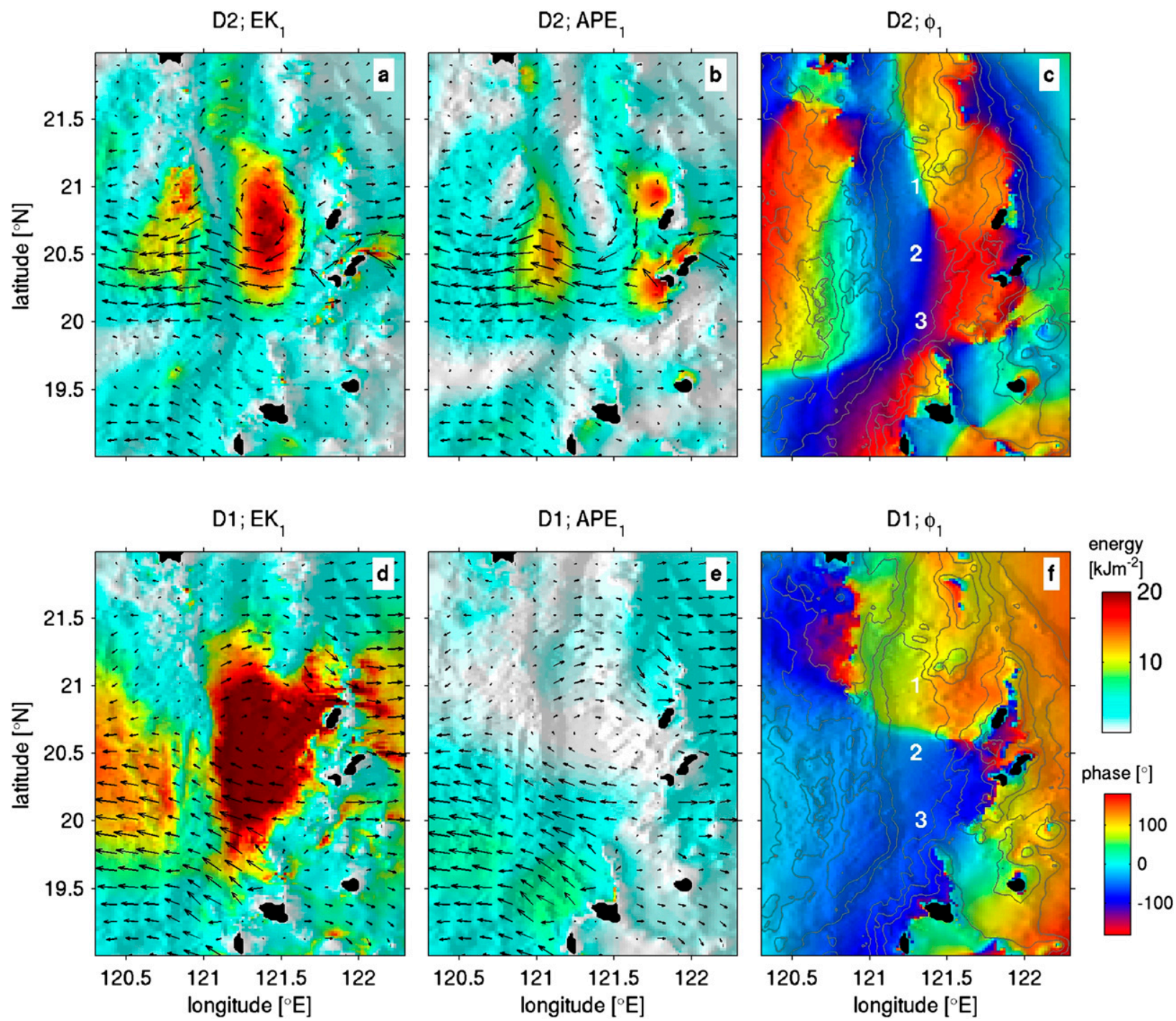

FIG. 9. The semidiurnal time-mean and depth-integrated mode-1 (a) horizontal kinetic energy and fluxes, (b) available potential energy and fluxes, and (c) phase of bottom perturbation pressure. The numbers refer to the PIES stations. The depth is contoured every $1000 \mathrm{~m}$. (d)-(f) As in (a)-(c), but for diurnal tides.

resonance is more sensitive to variations in the minor axis or $\Delta X$ than in the major axis or $\Delta Y: \Delta X \pm 10 \mathrm{~km}$ yields $\omega_{e} / \omega_{2} \pm 0.3$, and $\Delta Y \pm 10 \mathrm{~km}$ yields $\omega_{e} / \omega_{2} \pm 0.06$. This sensitivity to the separation distance is in agreement with the 2D results by BLK and Klymak et al. (2013).

We examine the influence of the combined 2D doubleridge resonance in the vertical plane normal to the ridges and the basin resonance in the horizontal plane on the conversion amplification by performing a number of idealized experiments. Two Gaussian ridges with equal heights $h=2500 \mathrm{~m}$ and standard deviations $\sigma=7.5 \mathrm{~km}$ on a rotating plane in a water depth $H=3000 \mathrm{~m}$ have various ridge separation distances: $\Delta X / \lambda_{1}=0.5,0.75$, and 1 , and north-south basin dimensions $\Delta Y / \lambda_{1}=0.5$,
$1,1.5$, and 2 , where $\lambda_{1}=144 \mathrm{~km}$ is the first-mode wavelength. The stratification is similar to the realistic 3D cases. The east-west boundaries are forced with semidiurnal barotropic currents such that the ridge-top velocity is about $0.5 \mathrm{~m} \mathrm{~s}^{-1}$. The north and south boundaries are closed to create an enclosed basin. In one additional set of simulations, where only $\Delta X$ is varied, the north and south boundaries are periodic; that is, the simulations are essentially 2D. The horizontal grid sizes are $3 \mathrm{~km}$ near the ridges and telescoped toward the boundaries. The model has 40 vertical layers that are WKB stretched. The cases are run for 4 days.

In these experiments the resonance is mainly governed by the ridge separation distance and not the north-south 


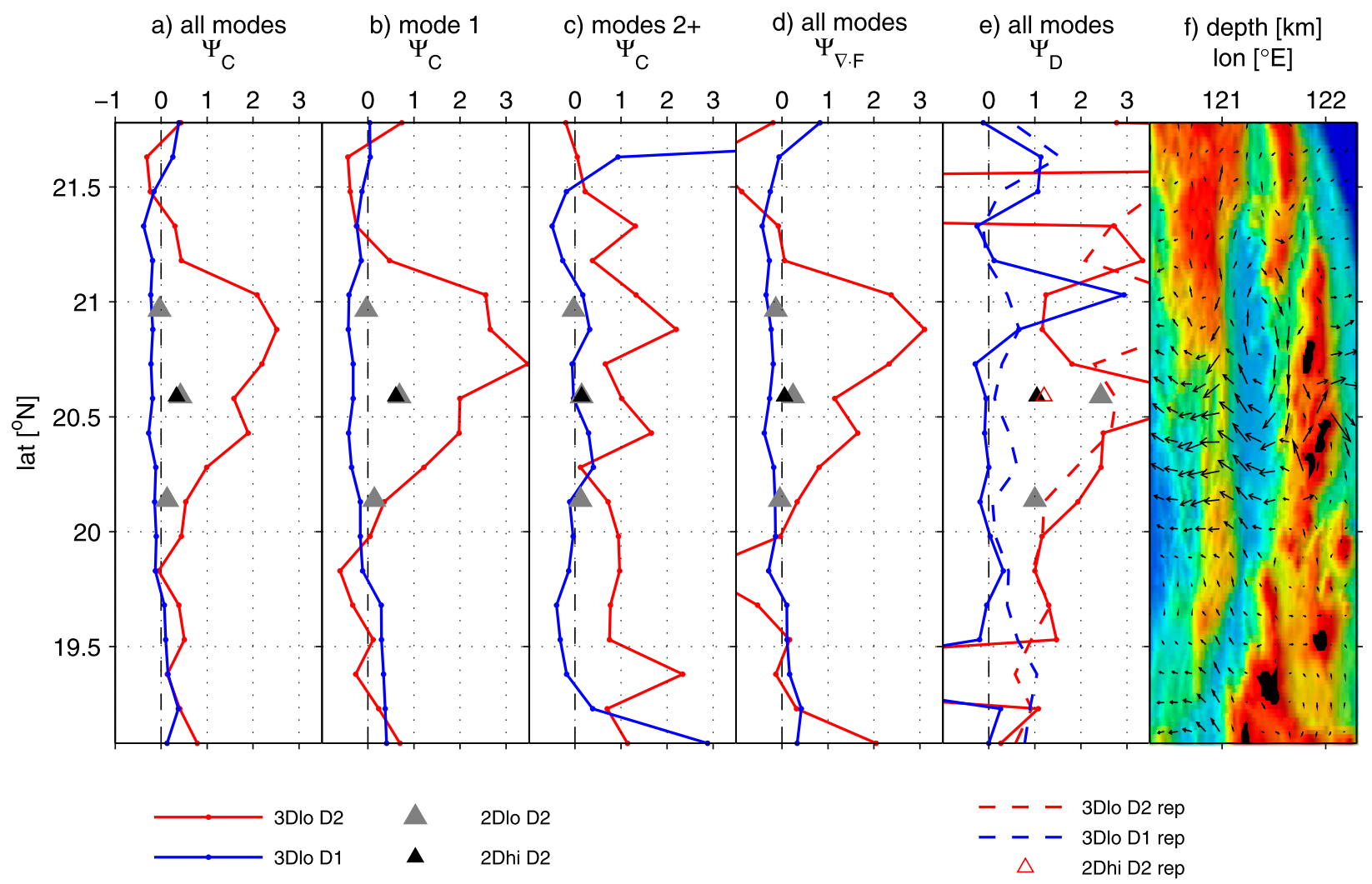

FIG. 10. The zonally integrated amplification of the conversion $C_{0 n}$ for (a) modes $1-10$, (b) mode 1 , and (c) modes $2-10$ as a function of lat and semidiurnal (D2) and diurnal (D1) frequencies for the 2D and 3D simulations. The amplification of (d) flux divergence and (e) diagnosed dissipation summed over all modes. Additional lines and markers are plotted for the amplification of the reported dissipation. The filled gray triangle of the northern transect of $2 \mathrm{D}_{\mathrm{lo}} \mathrm{D} 2$ has a diagnosed dissipation amplification value of -2.71 and falls outside the range of subplot (e). Legend abbreviations lo, hi, and rep refer to low resolution, high resolution, and reported dissipation, respectively. (f) The bathymetry in the Luzon Strait and semidiurnal mode-1 fluxes. The amplification for the diurnal $2 \mathrm{D}$ simulations matches the 3D simulations and is not shown.

basin length (Table 3 ), suggesting that resonance occurs in the vertical plane normal to the ridges. The strongest conversion occurs for $\Delta X / \lambda_{1}=0.5$. This configuration is close to resonance with an attractor connecting the ridge crests (Klymak et al. 2013). Hence, the higher-mode conversion is stronger than the first-mode conversion (Fig. 11a). Varying the north-south distance has only a marginal effect. The conversion of the periodic boundary cases with $\Delta X / \lambda_{1}=0.5$ and $\Delta X / \lambda_{1}=0.75$ in Table 3 is larger or equal to the cases with closed north and south boundaries, implying the amplification of the conversion is only due to the ridge separation distance.

A characteristic of resonant standing waves in an enclosed basin is the formation of the first vertical mode clockwise flux gyres with high kinetic energy in the gyre center. Single gyres form for $\Delta X / \lambda_{1}=0.5$ and 0.75 and $\Delta Y / \lambda_{1}=0.75,1.0$, and 1.5 , whereas two clockwise flux gyres form for $\Delta Y / \lambda_{1}=2.0$ (Fig. 11c). These clockwise gyres are absent for $\Delta X / \lambda_{1}=1.0$. In contrast to the double-ridge simulations with closed north and south boundaries, clockwise flux gyres do not form in the simulations with periodic boundaries. Instead, the fluxes are southward (northward) to the left (right) of the right (left) ridge. The closed north and south walls reflect this energy, but this does not enhance the resonance relative to the periodic boundary case.

TABLE 2. Area-integrated conversion $C$, flux divergence $\boldsymbol{\nabla} \cdot \mathbf{F}$, diagnosed $D_{\text {diag }}$ and reported dissipation $D_{\text {rep }}$, and amplification $\Psi$ summed over all modes for the 3D simulations for the central Luzon Strait between $20^{\circ}$ and $21.2^{\circ} \mathrm{N}$.

\begin{tabular}{lcccr}
\hline \hline & DR $(\mathrm{GW})$ & ER $(\mathrm{GW})$ & WR $(\mathrm{GW})$ & $\Psi$ \\
\hline $\mathrm{D} 2 ; C$ & 10.09 & 3.40 & 1.03 & 1.3 \\
$\mathrm{D} 2 ; \boldsymbol{\nabla} \cdot \mathbf{F}$ & 7.10 & 2.56 & 0.81 & 1.1 \\
$\mathrm{D} 2 ; D_{\text {diag }}$ & 3.00 & 0.84 & 0.22 & 1.8 \\
$\mathrm{D} 2 ; D_{\text {rep }}$ & 1.60 & 0.45 & 0.04 & 2.3 \\
$\mathrm{D} 1 ; C$ & 7.86 & 6.42 & 3.19 & -0.2 \\
D $; \boldsymbol{\nabla} \cdot \mathbf{F}$ & 5.72 & 4.96 & 2.52 & -0.2 \\
D1; $D_{\text {diag }}$ & 2.14 & 1.46 & 0.67 & 0.0 \\
D1; $D_{\text {rep }}$ & 2.51 & 1.68 & 0.27 & 0.3 \\
\hline
\end{tabular}


TABLE 3. The area-integrated, $\Delta Y$-normalized, and time-mean barotropic conversion to modes 1-10 in boldface and mode 1 alone $\left(\mathrm{kW} \mathrm{m}^{-1}\right)$ for the idealized double Gaussian-ridge experiments as a function of north-south domain size and separation distance. 2D refers to the experiments with the north and south periodic boundaries. The first-mode wavelength $\lambda_{1}=144 \mathrm{~km}$.

\begin{tabular}{lccc}
\hline \hline & \multicolumn{3}{c}{$\Delta X / \lambda_{1}$} \\
\cline { 2 - 4 }$\Delta Y / \lambda_{1}$ & 0.50 & 0.75 & 1.00 \\
\hline $2 D$ & $\mathbf{6 2 2} / 260$ & $\mathbf{4 3 7} / 302$ & $\mathbf{1 8 9} / 113$ \\
2.00 & $\mathbf{6 0 6} / 260$ & $\mathbf{4 2 2} / 293$ & $\mathbf{1 9 9} / 120$ \\
1.50 & $\mathbf{5 8 2} / 265$ & $\mathbf{3 9 1} / 278$ & $\mathbf{1 9 4} / 117$ \\
1.00 & $\mathbf{5 8 2} / 250$ & $\mathbf{4 0 5} / 276$ & $\mathbf{2 0 1} / 123$ \\
0.75 & $\mathbf{5 1 1} / 223$ & $\mathbf{4 0 8} / 275$ & $\mathbf{1 9 3} / 118$ \\
0.50 & $\mathbf{5 1 8} / 315$ & $\mathbf{2 8 1} / 208$ & $\mathbf{1 9 1} / 115$ \\
\hline
\end{tabular}

The feedback between the first-mode waves and the barotropic tide causes spatial variability in barotropicto-baroclinic conversion rates inside the trench (Fig. 11d). However, the zonally averaged conversion rates (Fig. 11a) as well as the amplification of the conversion (Fig. 11b) are fairly constant along the $y$ axis away from the boundaries. This contrasts with the realistic ridge experiments, in which the amplification of the conversion peaks near the center of the flux gyre.

In summary, the kinetic and potential energy patterns and the clockwise flux gyre in the idealized experiments are due to resonant basin waves. However, the $\Delta Y$-normalized conversion in the 3D double-ridge cases is independent of the basin length, and it is not larger than in the 2D simulation (Table 3 ). The resonance in these idealized experiments is therefore only a function of the ridge height and separation distance and independent of the along-ridge length. We therefore infer that in the realistic 3D cases, the resonance is similarly independent of along-ridge length.

\section{b. Nonuniform bathymetry}

In this section, we examine if the larger amplification in the 3D compared to the 2D cases at the central and northern transects (Fig. 10) can be attributed to the nonuniform bathymetry. We evaluate the amplification of the zonally averaged terms of the barotropic energy conversion to mode $1, C_{01}=1 / 2 A_{W} A_{p^{\prime}} \cos \left(\phi_{W}-\phi_{p^{\prime}}\right)$, where $A$ is the amplitude, $\phi$ is the phase, $W$ is the vertical barotropic velocity, and $p^{\prime}$ is the perturbation pressure at the bottom, along the west, east, and double ridges (Fig. 12).

The barotropic flow patterns and amplitudes in the 3D double-ridge simulations differ slightly from the singleridge cases in part because the flow is affected by the opposing ridge. As a consequence, the amplitude of the vertical velocity is amplified maximally by 0.5 (Fig. 12h), but this is not enough to explain the amplification of the conversion in the central strait (Fig. 12g).
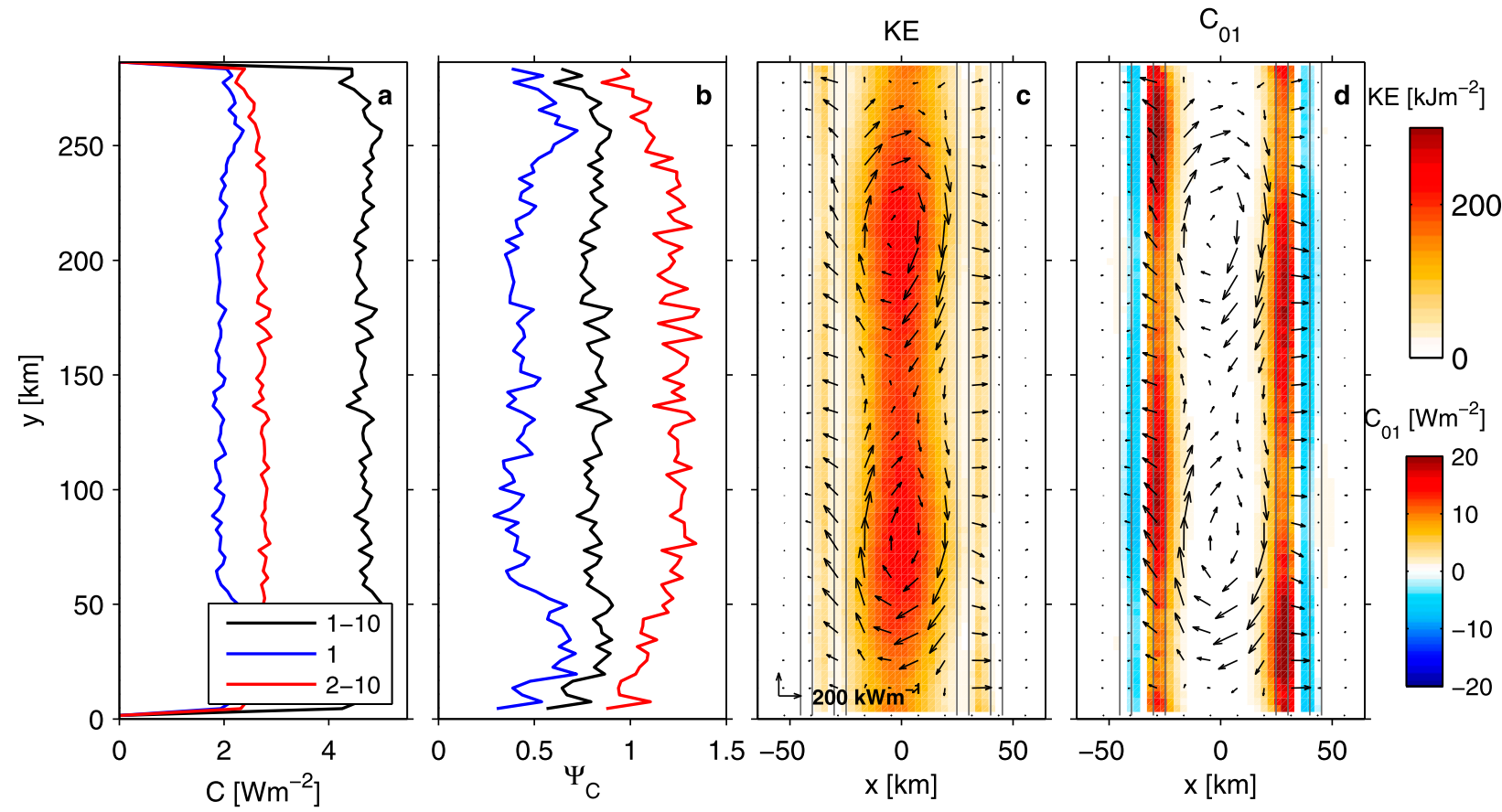

FIG. 11. The time-mean and zonally averaged (a) barotropic conversion to modes 1-10 (black), mode 1 (blue), and modes 2-10 (red) and (b) the associated amplification for the idealized double-ridge experiments with equal ridge heights for $\Delta X / \lambda_{1}=0.5$ and $\Delta Y / \lambda_{1}=2$. (c) The time-mean and depth-integrated kinetic energy and mode-1 fluxes. The depth contours are plotted every $1000 \mathrm{~m}$. (d) The time-mean barotropic conversion to mode 1 and mode-1 fluxes. 


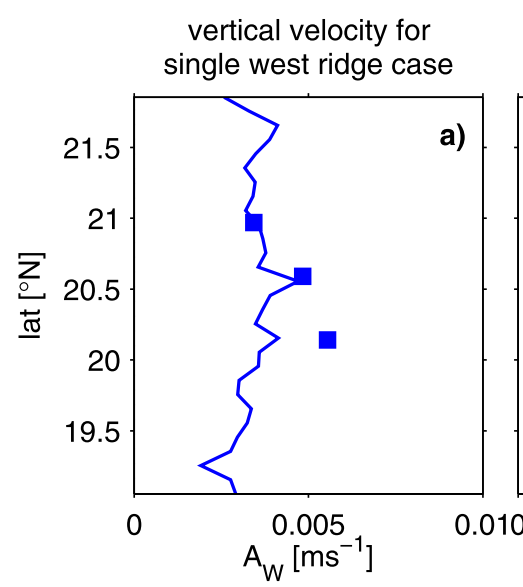

vertical velocity for single east ridge case
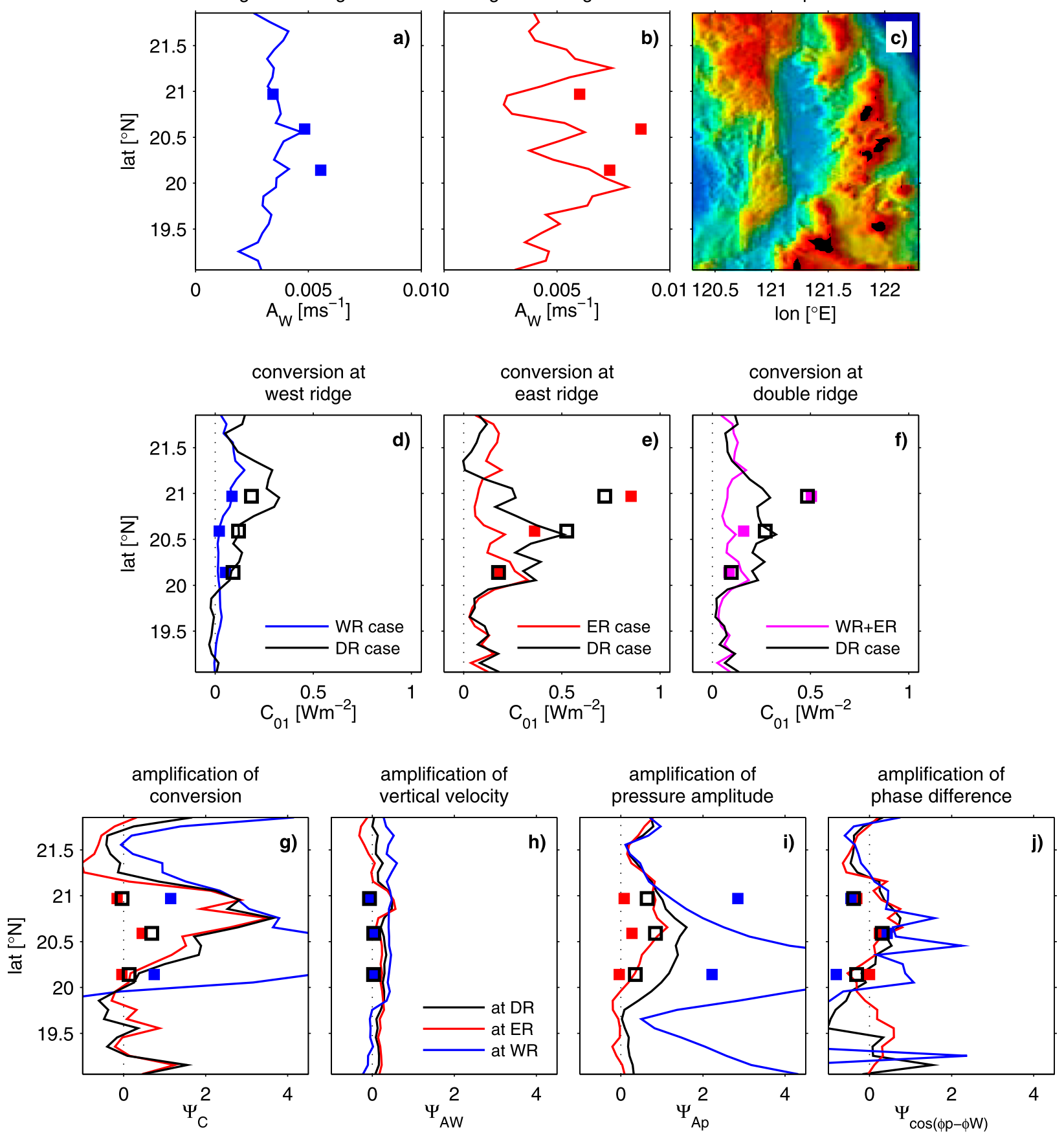

FIG. 12. (top) The zonally averaged amplitude of the vertical velocity for the single (a) WR and (b) ER cases and (c) the DR bathymetry. (middle) The semidiurnal barotropic- to first-mode conversion, zonally averaged over the (d) WR, (e) ER, and (f) DR for the single- and double-ridge cases. (bottom) The amplification (i.e., $\Psi$ ) of the zonally averaged (g) conversion, (h) amplitude of the vertical velocity, (i) amplitude of the bottom perturbation pressure, and (j) phase difference between the pressure and vertical velocity (positive means more in phase compared to the sum of the single-ridge cases). The lines (squares) are the 3D (2D) cases. The off-the-chart WR amplification in (g) and (i) at the central 2D transect is 4.5 and 6.2 . 

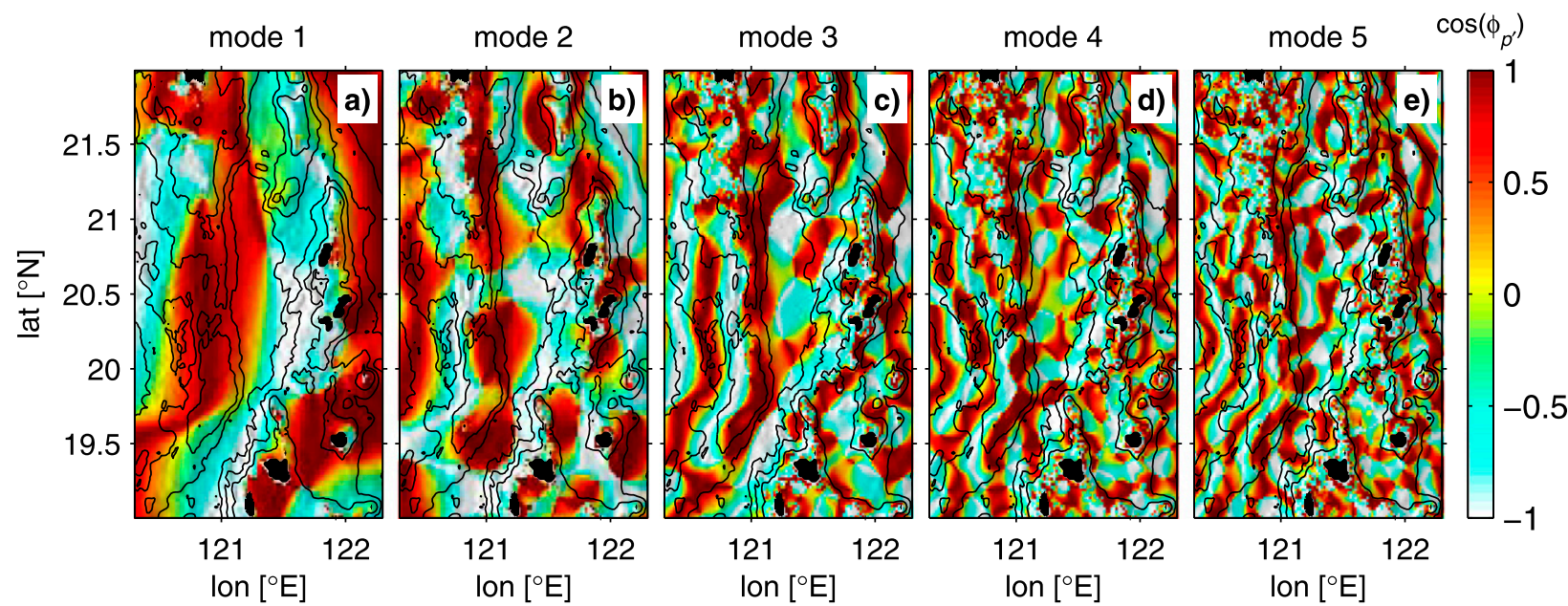

FIG. 13. Cosine of the phases of the semidiurnal perturbation bottom pressure for modes (a) 1, (b) 2, (c) 3, (d) 4, and (e) 5 for the double-ridge case. The patterns for the single-ridge cases are similar and are not shown.

A more significant 3D influence on the conversion amplification results from the blocking of the barotropic flow by the east ridge in the $3 \mathrm{D}$ simulations. In the $2 \mathrm{D}$ simulations all the barotropic flow is forced over the ridges, whereas in the 3D simulations the flow is forced to go around the east ridge at the northern transect (area I in Fig. 7). The vertical velocity amplitudes at the center and northern transects at the east ridge are therefore larger in the 2D compared to the 3D simulations (Figs. $12 \mathrm{a}, \mathrm{b})$, and consequently there is a stronger asymmetry in conversion between the two ridges in $2 \mathrm{D}$ than in $3 \mathrm{D}$ (Figs. 12d,e). Resonance is enhanced when the waves radiating from both ridges have a similar magnitude, as in the 3D simulations, confirmed by the zero zonal energy flux at the northern transect in Fig. 8a. These remotely generated waves are in phase with the local forcing causing the amplification to be large and equal at both ridges in 3D (Fig. 12g).

In addition to the $3 \mathrm{D}$ effects on velocity, the increased amplification of the conversion in the central strait in 3D (Fig. 12g) is governed by the amplification of the bottom perturbation pressure amplitude (Fig. 12i) and the phase difference between the pressure and the barotropic velocity (Fig. 12j). In the double-ridge case, the waves from the opposing ridges are more in phase with the local forcing in the $3 \mathrm{D}$ than in the $2 \mathrm{D}$ simulations at the northern transect, further enhancing the amplification. In contrast to the $2 \mathrm{D}$ case where remote waves always arrive perpendicular to the ridge, in the $3 \mathrm{D}$ case the remotely generated waves from the west ridge arrive at oblique angles at the east ridge at the northern transect, as indicated by the flux patters in Fig. 8a. This may contribute to a more constructive phasing in the 3D case.
In summary, the increased amplification in $3 \mathrm{D}$ is not due to the presence of the basin modes, but instead results from the increased symmetry in conversion between the east and west ridge in $3 \mathrm{D}$, a consequence of the blocking effect on the flow at the east ridge, and from the more constructive phasing between the barotropic tide and the remotely generated internal waves, arriving under oblique angles in 3D.

\section{c. Why is the resonance in mode 1?}

In the realistic $2 \mathrm{D}$ and $3 \mathrm{D}$ simulations, the total amplification of the semidiurnal conversion is mainly due to mode 1 , and the amplification of mode 1 occurs at larger spatial wavelength than the higher modes in the strait (cf. Figs. 10b,c).

The uniform, large-scale, double-ridge topography with its nearly constant ridge separation distance facilitates constructive first-mode interference during semidiurnal tides. The mode- 1 wave is more rectilinear, and the first-mode semidiurnal bottom perturbation pressure phase is constant and in phase with the barotropic forcing along the north-south axis (Fig. 13a). The smaller topographic scales generate higher modes (Zilberman et al. 2009). This topography is spatially less uniform, for example, because of its parallel subridges (Fig. 2). These generation sites cause higher-mode waves of a more radial kind that result in a spotty perturbation-pressurephase pattern (Figs. 13b-e). These higher modes are in and out of phase with the local barotropic forcing. The phase of the barotropic ellipses fluctuates less than $30^{\circ}$ over the strait, causing an amplification that changes over smaller spatial scales than the first mode (Fig. 10c).

Moreover, higher modes decay faster than low modes away from the ridge, making them less relevant for 
resonance. In the $3 \mathrm{D}$ and high- and low-resolution $2 \mathrm{D}$ single-ridge cases, the kinetic energy of modes 1-4 has decreased by less than $30 \%$, mode 5 by about $50 \%$, and mode 10 by about $80 \%$ over a distance of about $100 \mathrm{~km}$ away from the ridge. This decline is attributed to numerical dissipation and nonlinear wave-wave interactions (Lvov et al. 2012), such as thermocline scattering of the high-mode beam (Gerkema 2001; Gerkema and van Haren 2012), which cascades the energy to smaller scales that are dissipated.

Similar to Vlasenko et al. (2010), we find an amplification of the semidiurnal mode 2 by the double ridge in the central strait. However, Vlasenko et al. (2010) does not find that the westward-propagating mode- 1 waves are significantly enhanced, but they do not quantify this with conversion or flux computations.

\section{Conclusions}

This modeling study of the double-ridge internal tide interference in the Luzon Strait extends 2D numerical model experiments by BLK to three dimensions, focusing on the effect of cross-strait topography and flow variations on the double-ridge resonance. As in BLK, we study the double-ridge interference for semidiurnal and diurnal tides by omitting either the west or the east ridges. The 3D simulations are compared with additional 2D simulations performed at three zonal transects. We show that internal wave generation in $3 \mathrm{D}$ simulations can differ substantially from 2D simulations.

The 3D simulations agree reasonably well with the 2010 IWISE pilot measurements (Alford et al. 2011) and the PIES observations. Both the observations and simulations reveal (semi)diurnal first-mode standing waves in the 3.6-km-deep trench in the strait. Generally, the barotropic velocities are predicted within $\sim \pm 20 \%$ and the baroclinic fluxes within $\sim \pm 50 \%$ from the observed values. The barotropic velocities are better predicted at station $\mathrm{N} 2$ in the $3 \mathrm{D}$ than in the 2D simulations by BLK because of the topographic steering of the barotropic flow in the 3D simulations.

Similar to the 2D simulations by BLK, the barotropicto-baroclinic energy conversion, flux divergence, and dissipation are most strongly enhanced when semidiurnal tides dominate in the central strait, where the ridges are separated by about $90 \mathrm{~km}$ (about 0.6 times the first-mode wavelength). Coinciding with this area of strong amplification is a first-mode standing internal (Poincaré) wave with a clockwise flux gyre, large kinetic energy in its amphidromic point, and large available potential energy near the basin walls.

The most significant result of this study is that the amplification of the conversion in the double ridge in the central strait is several times larger than in the $2 \mathrm{D} \mathrm{nu}-$ merical simulations. The cause of this increased amplification in $3 \mathrm{D}$ is not the presence of $3 \mathrm{D}$ basin modes, because idealized 3D numerical model experiments show that the amplification of the conversion is only a function of the ridge separation distance and not of the along-ridge length. The difference in amplification is attributed instead to the 3D topography that causes a more equal wave generation at both ridges due to blocking of the barotropic flow at the east ridge and a more constructive phasing between the 3D first-mode waves and the barotropic Kelvin wave. Because of these $3 \mathrm{D}$ effects, we argue that internal wave generation is better simulated in 3D than 2D model experiments.

In the realistic $2 \mathrm{D}$ and $3 \mathrm{D}$ simulations, most of the semidiurnal resonance occurs for mode 1 . In these simulations, the high-mode resonance is less important because the higher modes do not have a consistent phase relationship with the barotropic forcing due to the nonuniform radiation from 3D topography.

Acknowledgments. We thank the Office of Naval Research (ONR) for funding this research under ONRDC32025354. ONR supported Jonathan Nash under N00014-09-1-0281, Harper Simmons under N0001410-1-0315, and Matthew Alford under N00014-09-01-0209. We acknowledge Robert Pinkel and Steve Ramp for providing their multibeam data. We are grateful to Samuel Kelly for the exchange of ideas. Finally, we thank three anonymous reviewers, whose suggestions helped to improve this manuscript.

\section{APPENDIX}

\section{Nonlinear versus Linear Terms}

In this appendix, we evaluate whether the linear analysis applied in this study can capture (the majority of) the internal wave dynamics in the Luzon Strait. We compare the magnitude of the nonlinear terms such as the advective energy flux and dissipation with linear terms in the time-mean depth-integrated hydrostatic nonlinear baroclinic energy equation (Kang and Fringer 2012; BLK). These terms are computed over the last 2.1 days of the unfiltered velocities and density fields from the two 3D simulations that feature semidiurnal and diurnal spring tides, respectively.

The flux of baroclinic energy comprises the "linear" pressure flux and the nonlinear advection of baroclinic kinetic and linear available potential energy. Similar to Kang and Fringer (2012), we use the total velocity for the advection of energy. When the baroclinic velocity is 
used, the advective flux magnitude is reduced by $\sim 50 \%$ in water shallower than $500 \mathrm{~m}$ because the barotropic velocities are large here. We compute the time-mean fluxes, take their absolute value, and average them over depth bins of $500 \mathrm{~m}$ for the entire strait bounded by $19.0^{\circ} \mathrm{N}, 22.0^{\circ} \mathrm{N}, 120.3^{\circ} \mathrm{E}$, and $122.3^{\circ} \mathrm{E}$. The barotropic velocities are stronger in the diurnal simulation (Figs. $3 \mathrm{c}, \mathrm{f})$. As a result, the absolute pressure and advective fluxes in the diurnal simulation are larger than in the semidiurnal simulation in Fig. A1a. The advective flux is proportional to $u^{3}$. Therefore, the advective fluxes have increased more than the pressure fluxes in the diurnal compared to the semidiurnal simulations (Fig. A1b). The diurnal advective flux becomes of the same magnitude as, or even larger than, the pressure flux in water shallower than $1000 \mathrm{~m}$, which is about $20 \%$ of the Luzon Strait (Fig. A1d). However, in water deeper than $2000 \mathrm{~m}$ $(3000 \mathrm{~m})$, which is about $55 \%(27 \%)$ of the strait, the (semi)diurnal advective fluxes are less than $20 \%$ (9\%) of the pressure fluxes. Although the advective fluxes are strongest in shallow water, they are relatively small compared to the pressure fluxes in deep water. Hence, the regional flux patterns are mainly dominated by the pressure fluxes, showing the standing wave patterns. Although the advective flux patterns are somewhat coherent in deep water, the direction and magnitude of the fluxes are poorly correlated with the pressure fluxes.

As the mostly linear first-mode internal waves from the strait propagate westward onto the shallower Chinese shelf, they disperse into nonlinear solitons. The ratio between the advective and pressure fluxes of these waves is proportional to the strength of their nonlinearity. Moum et al. (2007) observed nonlinear waves with an advective flux that is twice the pressure flux, which is certainly not the case in the Luzon Strait. Although there may be some nonlinear steepening close to the source, large solitary waves are not observed between the ridges in both the simulations and observations (Zhao et al. 2004). The relatively small advective flux in deeper water supports this. Note that the model's horizontal resolution of $2 \mathrm{~km}$ and its hydrostatic approach are well suited to simulate these large-scale firstmode waves in the strait, but they do not allow for a correct simulation of small-scale solitary waves. We cannot compute energy fluxes associated with nonhydrostatic pressure work, which are commonly generated by strong nonlinear waves. However, they are likely small in the Luzon Strait. Kang and Fringer (2012) showed that they are two orders of magnitude smaller than the hydrostatic pressure fluxes in Monterey Bay.

Breaking lee waves at supercritical topography cause the majority of the dissipation in the Luzon Strait (BLK). The 3D model does not resolve the breaking lee

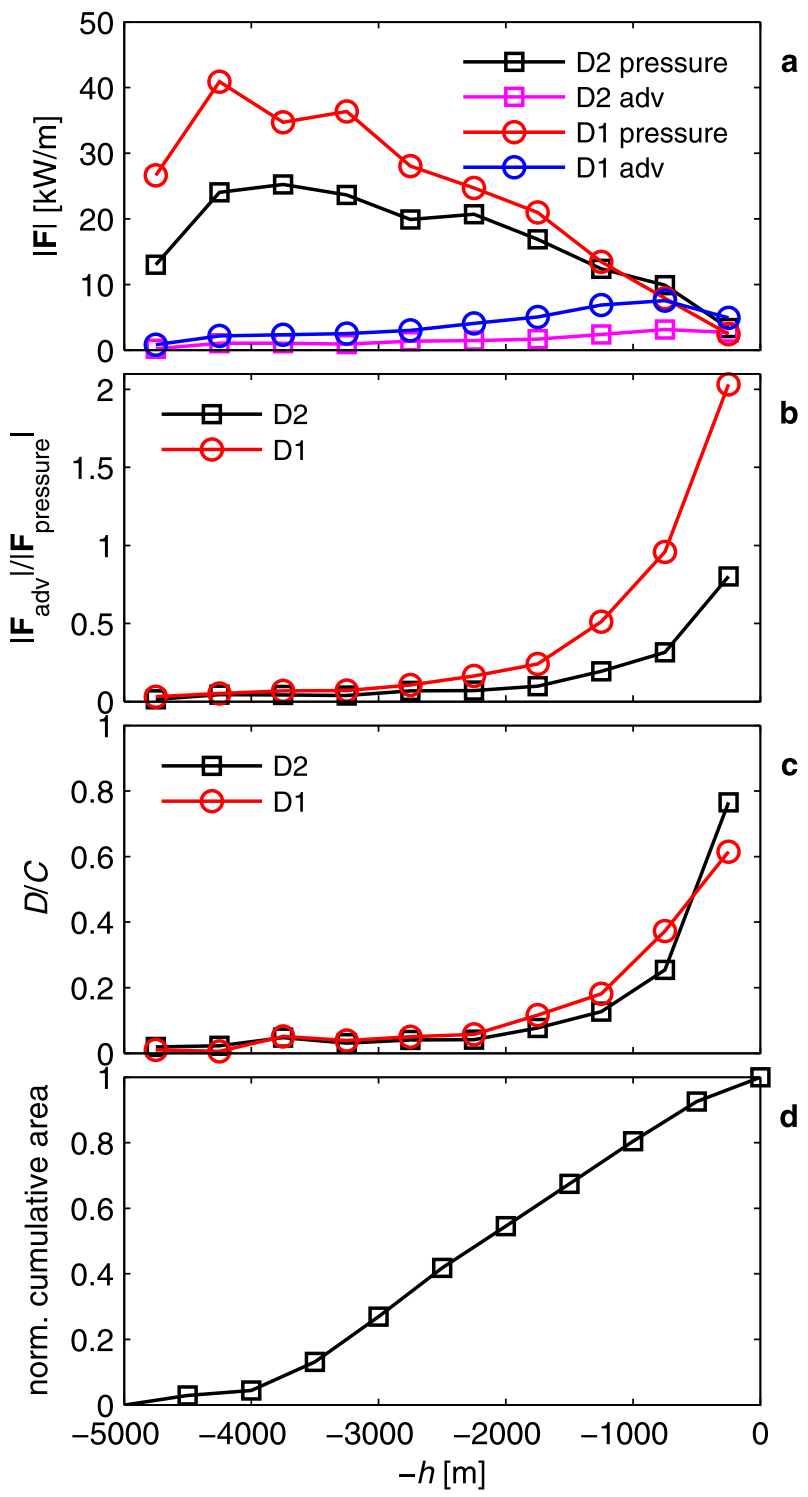

FIG. A1. (a) Area-averaged absolute time-mean fluxes for the 3D D2 and D1 simulations in the Luzon Strait. The labels pressure and adv refer to the pressure and advective fluxes computed using the unfiltered velocity and density model output. (b) The ratio between the advective and pressure fluxes. (c) The ratio between the reported dissipation and the conversion. (d) Cumulative surface area, normalized by the total area.

waves well. Hence, some of that energy is dissipated through quadratic bottom friction and horizontal viscosity. We compare the sum of the time-mean dissipation due to breaking waves, bottom friction, and horizontal viscosity with the linear conversion term in Fig. A1c. Similar to the advective flux, the dissipation becomes of the same order of magnitude as the linear conversion in shallow water $(z>-500 \mathrm{~m})$, while it is small in deep water. The semidiurnal dissipation is stronger than the 
diurnal dissipation in shallow water because the semidiurnal internal tides are resonant.

The time-mean contribution of the nonlinear interaction between the diurnal and semidiurnal frequencies is hidden in the advective flux and dissipation. It is an elaborate task to separate this nonlinear interaction. We do this for the pressure flux instead. The total baroclinic pressure flux due to diurnal and semidiurnal frequencies as a function of time and space can be decomposed as

$$
F=\left(u_{1}^{\prime}+u_{2}^{\prime}\right)\left(p_{1}^{\prime}+p_{2}^{\prime}\right)=u_{1}^{\prime} p_{1}^{\prime}+u_{2}^{\prime} p_{2}^{\prime}+u_{1}^{\prime} p_{2}^{\prime}+u_{2}^{\prime} p_{1}^{\prime},
$$

where $u^{\prime}$ is the baroclinic velocity, $p^{\prime}$ is the perturbation pressure, and subscripts 1 and 2 refer to diurnal and semidiurnal frequencies. The nonlinear contribution to the total flux is due to the cross terms $u_{1}^{\prime} p_{2}^{\prime}+u_{2}^{\prime} p_{1}^{\prime}$. When averaging over several tidal periods, this contribution asymptotes to zero. Averaged over the 2.1-day period, the time-mean flux due to the cross terms is $<3 \%$ of the sum of the diurnal and semidiurnal fluxes. This confirms the linearity of the pressure flux, as well as the conversion term, which is also quadratic in variables.

\section{REFERENCES}

Alford, M. H., and Coauthors, 2011: Energy flux and dissipation in Luzon Strait: Two tales of two ridges. J. Phys. Oceanogr., 41, 2211-2222.

Althaus, A. M., E. Kunze, and T. B. Sanford, 2003: Internal tide radiation from Mendocino Escarpment. J. Phys. Oceanogr., 33, 1510-1527.

Antenucci, J. P., and J. Imberger, 2001: Energetics of long internal gravity waves in large lakes. Limnol. Oceanogr., 46, 17601773.

Buijsman, M. C., J. C. McWilliams, and C. R. Jackson, 2010a: Eastwest asymmetry in nonlinear internal waves from Luzon Strait. J. Geophys. Res., 115, C10057, doi:10.1029/2009JC006004.

_ Y. Y. Kanarska, and J. C. McWilliams, 2010b: On the generation and evolution of nonlinear internal waves in the South China Sea. J. Geophys. Res., 115, C02012, doi:10.1029/2009JC005275.

— S. Legg, and J. Klymak, 2012a: Double ridge internal tide interference and its effect on dissipation in Luzon Strait. J. Phys. Oceanogr., 42, 1337-1356.

—, Y. Uchiyama, J. C. McWilliams, and C. R. Hill-Lindsay, 2012b: Modeling semidiurnal internal tide variability in the Southern California Bight. J. Phys. Oceanogr., 42, 62-77.

Csanady, G. T., 1967: Large-scale motion in the Great Lakes. J. Geophys. Res., 72, 4151-4162.

Dewey, R., D. Richmond, and C. Garrett, 2005: Stratified tidal flow over a bump. J. Phys. Oceanogr., 35, 1911-1927.

Echeverri, P., and T. Peacock, 2010: Internal tide generation by arbitrary two-dimensional topography. J. Fluid Mech., 659, 247-266.

Egbert, G., A. Bennett, and M. Foreman, 1994: TOPEX/Poseidon tides estimated using a global inverse model. J. Geophys. Res., 99 (C12), 24 821-24852.
Farmer, D., Q. Li, and J.-H. Park, 2009: Internal wave observations in the South China Sea: The role of rotation and non-linearity. Atmos.-Ocean, 47, 267-280.

Gerkema, T., 2001: Internal and interfacial tides: Beam scattering and local generation of solitary waves. J. Mar. Res., 59, 227-255.

_ , and H. van Haren, 2012: Absence of internal tidal beams due to non-uniform stratification. J. Sea Res., 74, 2-7.

Holloway, P. E., and M. A. Merrifield, 1999: Internal tide generation by seamounts, ridges, and islands. J. Geophys. Res., 104, $25937-25951$.

Jan, S., R.-C. Lien, and C.-H. Ting, 2008: Numerical study of baroclinic tides in Luzon Strait. J. Oceanogr. Soc. Japan, 64, 789-802.

_, C.-S. Chern, J. Wang, and M.-D. Chiou, 2012: Generation and propagation of baroclinic tides modified by the Kuroshio in the Luzon Strait. J. Geophys. Res., 117, C02019, doi:10.1029/ 2011JC007229.

Kang, D., and O. Fringer, 2012: Energetics of barotropic and baroclinic tides in the Monterey Bay area. J. Phys. Oceanogr., 42, 272-290.

Kelly, S. M., and J. D. Nash, 2010: Internal-tide generation and destruction by shoaling internal tides. Geophys. Res. Lett., 37, L23611, doi:10.1029/2010GL045598.

,,-- K. I. Martini, M. H. Alford, and E. Kunze, 2012: The cascade of tidal energy from low to high modes on a continental slope. J. Phys. Oceanogr., 42, 1217-1232.

Kerry, C. G., B. S. Powell, and G. S. Carter, 2013: Effects of remote generation sites on model estimates of $M_{2}$ internal tides in the Philippine Sea. J. Phys. Oceanogr., 43, 187-204.

Klymak, J. M., and S. Legg, 2010: A simple mixing scheme for models that resolve breaking internal waves. Ocean Modell. 33, 224-234.

— - _ , and R. Pinkel, 2010: High-mode stationary waves in stratified flow over large obstacles. J. Fluid Mech., 644, 19491964.

_ - M. Buijsman, S. Legg, and R. Pinkel, 2013: Parameterizing surface and internal tide scattering and breaking on supercritical topography: The one- and two-ridge cases. J. Phys. Oceanogr., 43, 1380-1397.

Kurapov, A. L., J. S. Allen, and G. D. Egbert, 2010: Combined effects of wind-driven upwelling and internal tide on the continental shelf. J. Phys. Oceanogr., 40, 737-756.

Largier, J. L., 1994: The internal tide over the shelf inshore of Cape Point Valley, South Africa. J. Geophys. Res., 99 (C5), 10023 10034.

Lavelle, J. W., and W. C. Thacker, 2008: A pretty good sponge: Dealing with open boundaries in limited-area ocean models. Ocean Modell., 20, 270-292.

Legg, S., and J. Klymak, 2008: Internal hydraulic jumps and overturning generated by tidal flow over a tall steep ridge. J. Phys. Oceanogr., 38, 1949-1964.

Li, Q., and D. Farmer, 2011: The generation and evolution of nonlinear internal waves in the deep basin of the South China Sea. J. Phys. Oceanogr., 41, 1345-1363.

— D. M. Farmer, T. F. Duda, and S. Ramp, 2009: Acoustical measurement of nonlinear internal waves using the inverted echo sounder. J. Atmos. Oceanic Technol., 26, 2228-2242.

Lvov, Y. V., K. L. Polzin, and N. Yokoyama, 2012: Resonant and near-resonant internal wave interactions. J. Phys. Oceanogr. 42, 669-691.

Marshall, J., A. Adcroft, C. Hill, L. Perelman, and C. Heisey, 1997: A finite-volume, incompressible Navier Stokes model for studies of the ocean on parallel computers. J. Geophys. Res., 102 (C3), 5753-5766. 
Martini, K. I., M. H. Alford, J. Nash, E. Kunze, and M. A. Merrifield, 2007: Diagnosing a partly standing internal wave in Mamala Bay, Oahu. Geophys. Res. Lett., 34, L17604, doi:10.1029/ 2007GL029749.

Moum, J. N., J. M. Klymak, J. D. Nash, A. Perlin, and W. D. Smyth, 2007: Energy transport by nonlinear internal waves. J. Phys. Oceanogr., 37, 1968-1988.

Munk, W. H., and C. Wunsch, 1998: Abyssal recipes II: Energetics of tidal and wind mixing. Deep-Sea Res., 45, 1977-2010.

Nash, J. D., E. Kunze, C. M. Lee, and T. B. Sanford, 2006: Structure of the baroclinic tide generated at Kaena Ridge, Hawaii. J. Phys. Oceanogr., 36, 1123-1135.

Ponte, A. L., and B. D. Cornuelle, 2013: Coastal numerical modelling of tides: Sensitivity to domain size and remotely generated internal tide. Ocean Modell., 62, 17-26.

Rainville, L., and R. Pinkel, 2006: Propagation of low-mode internal waves through the ocean. J. Phys. Oceanogr., 36, 1220-1236.

Ramp, S. R., and Coauthors, 2004: Internal solitons in the northeastern South China Sea. Part I: Sources and deep water propagation. IEEE J. Oceanic Eng., 29, 1157-1181.

Shimizu, K., 2011: A theory of vertical modes in multilayer stratified fluids. J. Phys. Oceanogr., 41, 1694-1707.

Simmons, H. L., R. W. Hallberg, and B. K. Arbic, 2004: Internal wave generation in a global baroclinic tide model. Deep-Sea Res. II, 51, 3043-3068.
Smith, W. H. F., and D. T. Sandwell, 1997: Global seafloor topography from satellite altimetry and ship depth soundings. Science, 277, 1957-1962.

St. Laurent, L. C., S. Stringer, C. Garrett, and D. Perrault-Joncas, 2003: The generation of internal tides at abrupt topography. Deep-Sea Res. I, 50, 987-1003.

Vlasenko, V., N. Stashchuk, C. Guo, and X. Chen, 2010: Multimodal structure of baroclinic tides in the South China Sea. Nonlinear Processes Geophys., 17, 529-543.

Wang, D.-P., 2012: Diurnal modulation of semidiurnal internal tides in Luzon Strait. Ocean Modell., 59-60, 1-10.

Zhao, Z., and M. Alford, 2006: Source and propagation of internal solitary waves in the northeastern South China Sea. J. Geophys. Res., 111, C11012, doi:10.1029/2006JC003644.

_ - V. Klemas, Q. Zheng, and X.-H. Yan, 2004: Remote sensing evidence for baroclinic tide origin of internal solitary waves in the northeastern South China Sea. Geophys. Res. Lett., 31, L06302, doi:10.1029/2003GL019077.

Zilberman, N. V., J. M. Becker, M. A. Merrifield, and G. S. Carter, 2009: Model estimates of $M_{2}$ internal tide generation over Mid-Atlantic Ridge topography. J. Phys. Oceanogr., 39, 2635-2651.

— M. A. Merrifield, G. S. Carter, D. S. Luther, M. D. Levine, and T. J. Boyd, 2011: Incoherent nature of $M_{2}$ internal tides at the Hawaiian Ridge. J. Phys. Oceanogr., 41, 2021-2036. 